\title{
Economic geography of contagion: A study on Covid-19 outbreak in India*
}

\author{
Tanika Chakraborty ${ }^{+}$ \\ Anirban Mukherjee ${ }^{++}$
}

\begin{abstract}
We propose a mechanism based on regional inequality in economic activity to explain the heterogeneity in the spread of Covid-19 and test it using data from India. The contagion is expected to spread at a higher rate in regions characterized by greater movements of goods and service. We argue that mobility will be higher in regions with greater degree of intra-regional inequality in economic activity. Such regions are usually characterized by core-periphery economic structure in which the periphery remains dependent on the core for the supply of jobs, goods, and services. Such dependence leads to greater degree of mobility between the core and periphery which in turn leads to higher rate of contagion. Using nightlights data to measure regional inequality, we find evidence in support of our hypothesis. Using mobility data, we provide direct evidence in support of our proposed channel; the positive relationship between regional inequality and Covid-19 infection is driven by mobility. Our findings suggest that policy responses to contain Covid-19 contagion needs to be heterogeneous across India where the priority areas can be chosen ex-ante based on a regional inequality-based criterion.
\end{abstract}

JEL Codes: I15; I18; R1

Keywords: Covid-19; contagion; core-periphery; nightlight; mobility

Conflict of Interest: The authors declare that they have no conflict of interest.

\footnotetext{
${ }^{*}$ We thank two anonymous referees and the seminar participants at Delhi School of Economics and South Asian University for their helpful comments. We are particularly grateful to Robert Carl Michael Beyer for the nightlights data and helpful feedback on the paper. We are thankful to Nishant Chadha and India Development Foundation for helping us with the mobility data from the Facebook Data for Good project. Srutakirti Mukherjee and Vishal Nagwani provided excellent research assistance.

Chakraborty acknowledges the financial support provided by IIM Calcutta for this research.

+ Indian Institute of Management Calcutta, India; Email: tanika@iimcal.ac.in

${ }^{++}$University of Calcutta, India; Email: ameco@caluniv.ac.in
} 


\section{Introduction}

The Covid-19 epidemic that started in China in November 2019 has already created havoc worldwide. One of the striking features of the Covid-19 epidemic is the cross-country variation in terms of the number of infections and deaths. Even when we look within countries, we find significant regional variation in the extent of the contagion (Figure 4 shows the variation across India). There could be several factors such as population density, urbanization, available infrastructure to carry out effective quarantine, reporting errors etc., that explain such cross-regional differences. In this paper, we propose an economic geography-based explanation. We argue that the degree of contagion depends on the degree of movement of people and goods between different regions which in turn depends on the geographical pattern of regional development. Specifically, we argue that regions with unequal distribution of economic activity are characterized by greater degree of movements of goods and people and, hence, run a higher risk of contagion than the areas characterized by regional equality.

The theoretical structure underlying our argument draws heavily on the new economic-geography theory of economic development (see Krugman, 1991; Krugman and Venables, 1995). This theory argues that conditional on the level of transport cost, the process of economic development may end up creating a, heavily industrialized, small core area surrounded by a large non-industrial periphery. Such areas are typically characterized by regional inequality where goods are produced in the industrialized core and distributed to the periphery while people move from the periphery to the core in search of jobs. Hence, one may logically expect greater degree of movements of goods and people in such an unequal region compared to relatively equal regions where sub-regions are self-sufficient. It is the degree of movement of goods and people that connects regional inequality with the risk of contagion. In an unequal region, the remote subregions (periphery) are all connected with the economic hub (core) and therefore to each other. If any of the hubs get affected -- which is a likely scenario as hubs are densely populated -- the contagion is more likely to spread to the remote areas as well, through the movements of goods and people. Given the heavy dependence of peripheral areas on the core in a core-periphery structure, in the event of an outbreak, any attempt to isolate the core will impose a very high economic cost on the peripheries.

While economic geography could potentially explain at least part of the cross-country differences in the spread of infection, conducting the empirical analysis on cross country samples hardly makes any sense as differences across countries could be due to a host of factors - like institutional, cultural, political -which are difficult to control. We, instead, explain variations in infection rates, by variations in the extent of the core-periphery economic structure, across regions within a country - India. We argue that a state showing a 
greater degree of within-state regional inequality in economic activity will also have greater intra-state mobility which in turn contributes to a faster spread of the epidemic.

We propose a nightlight-based measure of inequality in economic activity and test our hypothesis using data on the spread of Covid19, and mobility, between April 2020 and February 2021 along with information on the pre-covid incidence of nightlights, across the districts of India. Night time luminosity is a wellestablished measure to compare economic and industrial activity across countries, as well as across regions within a country (Henderson et al., 2012; Prakash et al., 2019). We construct an index of regional inequality in economic activity based on night-time luminosity data, across the districts of India, to measure the coreperiphery structure of a region; higher inter-district nightlight inequality, within a region, reflects a stronger core-periphery structure in that region. ${ }^{1}$

The Covid-19 data that we use is reported at the district level. India consists of 28 states and 8 union territories which are further divided into districts. At the time of the last census in India, in 2011, there were 640 districts in India. ${ }^{2}$ The districts are further subdivided into sub-districts and sub-districts into blocks. Given that the districts are the unit of observation, inequality must be measured at a level bigger than the district. Hence, the administrative level above the district - the state -- is the natural choice. However, Covid handling policies are determined at the state level and the organization of economic activities is also likely to be state-specific. Hence, state level unobserved heterogeneity might confound the observed relationship between nightlight inequality and covid spread. Measuring inequality at the state level, however, prevents us from using the state fixed effect to mitigate the problem of unobserved heterogeneity at the state level. We, therefore, construct nightlight inequality at the sub-state level, in the neighbourhood of a district and estimate its effect on the extent of the contagion in that district and use state fixed effects and state level linear daily trends in our empirical specifications (see Section 2 for details of the inequality measure).

While this strategy allows us to control for the unobserved heterogeneity at the state level, some concerns regarding identification remain. For example, we are unable to account for the possibility of unobserved heterogeneity at the district level since our measure of regional inequality does not vary within a district. In the Indian context, the institutional decisions are taken at the state level which our fixed effect strategy takes care of. We have also taken control of district level nightlight which accounts for the level of economic activities and associated factors at the district level. However, we cannot completely rule out the possibility

\footnotetext{
${ }^{1}$ We use night time luminosity and nightlights interchangeably in this paper.

2 The number of districts has increased over time as they have sometimes been bifurcated for administrative ease. As of 2021, there are 740 districts.
} 
of unobserved heterogeneity emanating from factors such as cultural differences across district clusters. These factors may lead to heterogeneity of policy implementation at the district level. For instance, a district that has better health infrastructure and stricter Covid-policy implementation could also belong to a region that is more equal in terms of economic activities. To address this, we control for a wide range of demographic, economic and disease-environmental covariates at the district level. Our findings remain robust to the staggered inclusion of these covariates. Our primary findings suggest that higher nightlight inequality is associated with a greater extent of contagion.

We argue that movement of people plays a key role in explaining this finding - inequality in economic activity within a region leads to higher mobility which in turn drives the contagion. We provide evidence on this channel in three ways. First, we use differences in potential mobility over lockdown and unlock periods, announced by the Indian government, to test whether the relationship between Covid-19 and regional inequality varied across the different lockdown phases. Second, we use mobility data from the Facebook Data for Good project to study the mechanism directly. Third, we use unemployment rates as a proxy for movement of people (or lack thereof) and investigate its interaction with the core-periphery structure. ${ }^{3}$ The heterogeneity analysis using phases of lockdown shows that the core-periphery structure contributes to the spread of the Covid-19 infection only when the economy is not under lockdown. The results are absent or muted during the lockdown periods and early phases of unlock. We also find that movement of people, as measured by the Facebook mobility data, is strongly correlated with our measure of regional inequality and is the main driver of the primary relationship. Finally, using unemployment as a proxy for lower mobility, we find that for any two states with the same level of inequality in nightlights, the one with higher levels of baseline unemployment, experience a lower extent of contagion.

The findings in this paper contribute to the section of the literature which looks at the policy response of governments in face of Covid-19. Milani, 2021, shows how social connectedness across countries explain the cross-country similarity in social responses to Covid pandemic. In the pre-vaccine phase of the contagion, the most common strategy practiced by any government was that of lockdown which is complemented by health policies whose implementation and success in curbing the contagion varied across countries (Chiplunkar and Das, 2021; Qiu et al., 2020). Lockdown policies are seen to affect economies in various nuanced ways. Bonacini et al., 2021b, for example, showed that lockdown induced work-from-home practice creates the risk of exacerbating income inequality. Bonacini et al., 2021, showed how people's expectation formation can mitigate the effect of lockdown policies. We have seen that whenever a lockdown was

\footnotetext{
${ }^{3}$ In Section 5.4.3 we provide evidence that higher unemployment is related to lower mobility in India.
} 
imposed, often it was imposed homogeneously across all the regions of a country. Estimates of costs of a general lockdown have varied widely but they are all unequivocally large. In the context of India, for example, quite a few papers estimated the negative impact of lockdown policies on economic outcomes (Beyer et al., 2020, 2021). Hence, many have argued in favor of targeted lockdowns (Brunnermeier, 2021). The findings in our paper suggest a road map of selective lockdown that can minimize the economic costs.

Our findings suggest that contagion is likely to be more severe in areas characterized by higher mobility and that nightlight inequality is an easily available proxy of mobility. Accordingly, lockdown policies can be heterogeneous and the variations can be determined based on pre-existing nightlights data. While lockdown has been the most popular intervention to prevent the Covid 19 contagion, it is important to note that the policy implication of our paper applies to all possible anti-epidemic measures. After the Covid-19 vaccines were invented, vaccination spearheaded the anti-Covid policy measures. Nevertheless, the approach to the use of the policies remains homogeneous, as in the case of lockdowns - they were implemented with similar intensity across the country. We propose an ex-ante selection criterion. We suggest that any anti-epidemic policy -- be it creation of special Covid hospitals, lockdown or vaccination - can be more effective if implemented on a priority basis in areas with higher inequality in economic activity. However, we must emphasize that these are only suggestive policy implications. While we have controlled for a wide range of covarying factors at the district level that could drive our results, it is not possible to rule out unobserved heterogeneity completely. In the absence of strict exogeneity conditions, we must exercise caution in interpreting the results of our paper causally.

Our paper is structured in the following way: We elaborate our argument and issues related to our framework in Section 2. We discuss the data and descriptive statistics in section 3, the empirical strategy in section 4, and the results in section 5 . In section 6 , we conclude.

\section{Conceptual Framework}

In this paper, we explore the relationship between regional inequality in economic activity and Covid-19 infection. There are two key concepts that need to be explained before we discuss our empirical analysis. The first one concerns the mechanism underlying our hypothesis and the second one is related to the measurement of regional inequality in economic activity. The mechanism underlying our hypothesis is based on mobility. We argue that the degree of contagion will be greater in regions characterized by greater intraregional mobility and such mobility is expected to be higher in areas with higher inequality in the distribution of economic activity. The areas with higher dispersion in the distribution of economic activity are the ones characterized by a core-periphery structure. The alternative to this structure will be that of regional autarky 
where a region consists of a few similarly developed sub-regions consisting of both more and less developed sectors. ${ }^{4}$ One implication of the creation of the core-periphery structure is increased movements of commodity and people between core and periphery; goods and services move from the core to the periphery. It could also be the case that the more economically active core has higher living costs and labor may commute to work from the cheaper periphery to the more expensive core, once again leading to greater mobility in a region characterized by the core-periphery economic structure. On the other hand, if a region consists of a few areas with similar levels of economic activity, we expect less movements between such areas. Therefore, we expect greater movements of people and, consequently, higher degree of contagion at the time of epidemic in regions characterised by the core-periphery structure. This argument forms the basis of our empirical strategy.

We use regional inequality in economic activity as a proxy for the core-periphery structure and hypothesize that higher regional inequality will be associated with greater degree of Covid-19 infection, through mobility. One major reason for using the measures of inequality instead of mobility itself is the availability of data. The nightlight-based inequality measures are more readily available than measures of mobility.

The second concept that deserves discussion is the measurement of regional inequality. We use nightlight to construct a measure of regional inequality. The use of nightlights to find spatial patterns of economic clusters is not an entirely novel approach. However, the exploratory spatial data analysis, also called ESDA techniques, applied in the literature are commonly used to capture spatial spill-over (Rodríguez-Pose et al., 2013; Rodríguez-Pose and Tselios, 2011; Tselios and Stathakis, 2020) and are not suitable for answering our research question. We instead use regional nightlights data to construct measures of regional inequality. Below, we discuss the measure of regional inequality that we use.

Covid-19 data in India is available at the district level. To match this data structure we treat districts as the unit of observation whose level of economic activity is measured by the level of nightlight. To test our hypothesis, we need to measure inequality across districts which must be measured at a supra-district level. The natural choice of such supra-district level is state. In this case, we rank the districts of each state according to their respective nightlights and then measure the ratio of nightlights at the $90^{\text {th }}$ and $10^{\text {th }}$ percentile (P90/P10 ratio) for a state. The use of the P90/P10 ratio as the measure of inequality is now widely accepted in the literature on income inequality (Burkhauser et al., 2009; Kijima, 2006; Piketty, 2014). Unlike

\footnotetext{
${ }^{4}$ Some studies suggest that the degree of core-periphery-ness is higher in more developed regions; such pattern is found from the studies on Africa (Mveyange, 2015) and India (Singhal et al., 2020). However, the relationship between regional inequality and economic development is orthogonal to our hypothesis.
} 
other measures such as Standard Deviation and Gini Coefficient which consider all intermediate income groups, this ratio makes a direct comparison between the richest and the poorest. In our case, it compares between the most active and the least active districts and therefore, brings out the sharpness of inequality. In other words, it measures the economic distance between the core (the most active) and the periphery (the least active). We argue that greater the distance between the core and the periphery in terms of economic development (as measured by nightlight), the greater is the dependence of the periphery on the core for jobs and necessary supplies. This in turn entails greater movements of goods and people between the core and the periphery and higher rate of Covid 19 infection.

However, a measure of regional inequality at the state level renders regression with state fixed effects infeasible. Inter-state comparisons are difficult to rely on given that most policies, especially health policies are decided and implemented at the state level. Hence even though we use state level measure of regional inequality in our baseline regression, for the rest of our empirical exercises, we use regional inequality measured at the district neighbourhood level where the neighbourhood of a district $i$ is defined as the cluster of districts that share borders with the district $i$. District $i$ itself is included in the cluster. However, for each district there are at most 4-5 neighbouring districts and calculating the P90/P10 for such a small group is not meaningful. We therefore calculate the ratio between the minimum and maximum nightlight in the districtneighbourhood and subtract it from 1 . The resulting measure becomes a function of the difference between the maximum and minimum nightlight in the neighbourhood which is a measure of nightlight dispersion. We formally introduce this measure in section 3.2.4. In essence, both measures capture the distance between the most economically active and the least economically active district in the region which in our case can be interpreted as the distance between the core and the periphery. In our theoretical framework, we argue that the higher is the nightlight dispersion within a district-neighbourhood, the higher will be the mobility within the district-neighbourhood which, in turn results in greater degree of contagion in that area.

We have two key mechanisms underlying our theoretical argument. First, mobility in a districtneighbourhood, is a rising function of the variation in economic activities within the neighbourhood. Second, the degree of contagion is a rising function of mobility. Together, these two channels imply that Covid-19 spreads more in districts that belong to neighbourhoods where the degree of variation in economic activities is higher. 


\section{Data and Descriptive Statistics}

\subsection{Covid-19 infection: state-wise variation}

In this section, we provide an outline of the inter-state variation in Covid-19 infection across India. Since health is under the jurisdiction of state governments in India, district level information on Covid19 infections in India is provided by each state. But there was a significant heterogeneity in terms of data publication format across states, making data gathering even more challenging. During our study period (January, 2020January, 2021), there was no central database that published and updated either patient level information or even district level information on tests and detections for all India on a daily basis. Fortunately, a crowd sourced initiative, Covid19india came up in India in the early days of the pandemic which gathered data from various publications of state governments available online, such as twitter feeds of different state's health departments, press releases and bulletins. They created a publicly available database of Covid19 infections in India. We obtained all information related to Covid19 from this database available at https://www.COVID19india.org/. Appendix Table A1 reports details on the nature of the data available for each state over different periods of time during our study period.

Our analysis in this paper studies the spread of the disease from May 4, 2020, onwards, when the third phase of the nationwide lockdown started in India. There are two reasons why we choose this cut-off date. First, the district level database of Covid19india.org starts from this date, possibly because the quality of data gets better from this period as different state governments start reporting data in a consistent fashion. Second, our theory is relevant when there are some movements of goods and people. In the first month of lockdown (lockdown 1 and 2 i.e. from March, 25, 2020 to May 3, 2020) very stringent restrictions were imposed on business and vehicles. From $4^{\text {th }}$ May, 2020, the nationwide lockdown was eased for the first time with several relaxations. Further, we include the following major states in our sample ${ }^{5}$ : Andhra Pradesh, Bihar, Chhattisgarh, Gujarat, Haryana, Himachal Pradesh, Jammu and Kashmir, Jharkhand, Karnataka, Kerala, Madhya Pradesh, Maharashtra, Odisha, Punjab, Rajasthan, Tamil Nadu, Uttar Pradesh (U.P), Uttarakhand, West Bengal. As of February 1, 2021, the last date for our data, these states together accounted for around $84 \%$ of our data.

Figure 1 shows the distribution of Covid infections across states as of $1^{\text {st }}$ February, 2021. 10 states account for more than $75 \%$ of all cases in the country. Hence, for the rest of the descriptive statistics on Covid-19 infection in India, we report expositions based on these 10 states.

\footnotetext{
${ }^{5}$ Our estimation sample includes 19 major states. It excludes among others Delhi and other Union Territories. Since Union Territories are not divided in to districts, we cannot calculate nightlight inequality. Also, for Delhi, the Covid data is reported for Delhi as a whole. Consequently, there is no district level variation within Delhi. And nightlight inequality does vary over time. Hence it will mean a single nightlight inequality measure will explain variations in Covid over time.
} 


\section{Figure 1: Share of Covid-10 confirmed cases in 10 leading states}

Figure 2 shows the evolution of Covid over time in the top 10 states. As has been well known, Maharashtra led by a big margin, in terms of total number of infections, over the entire period from the onset of the pandemic in India to early February 2021, when our data ends. Maharashtra was followed by Delhi for a short while. But Delhi was quickly surpassed by Andhra Pradesh, Tamil Nadu, Karnataka and Uttar Pradesh by August 2020. The rest of the states in the top 10, viz. West Bengal, Bihar, Telangana and Assam remained relatively closer to each other for the entire period of study.

\section{Figure 2 : Time series of Covid-19 confirmed cases in 10 leading states}

While this graph gives an overall idea about the spread of the disease across India, it fails to account for the difference in sizes of these states. For example, comparing the entire state of Maharashtra with Delhi may not be very informative given the large difference between these states in terms of population and area.

\section{Figure 3: Total confirmed Covid-19 cases per 100 thousand population of the states}

Figure 3 depicts the evolution of Covid-19 over time in the top 10 states but normalized by population sizes of each state. States such as Maharashtra and Tamil Nadu which dominate the Covid-19 scenario in India in terms of total number of patients rank much lower when we consider per capita infection spread. Here, Delhi surpasses all other states by a large margin with the gap starting to show up significantly from early June 2020. Andhra Pradesh, which was ranked low initially, almost caught up with Delhi by September 2020. Maharashtra and Tamil Nadu are the next in the list which remained much below Delhi but much higher up than the other states throughout the period. Around September 2020, Karnataka made a big jump and almost caught up with Maharashtra and Tamil Nadu. Next in the order are Telangana and Assam, followed by West Bengal. Uttar Pradesh, being the largest state was high up in the list of total infections, but towards the end in the list of per capita infections, along with Bihar.

\section{Figure 4: A district level map of daily confirmed cases of Covid-19}

Figure 4 presents the spread of the contagino at the district level averaged over days until $31^{\text {st }}$ January, 2021. In the map darker shades indicate more cases while the lighter shades represent less cases. We see a wide variation in the number of Covid-19 cases across India with more cases in more industrialized Southern states.

\subsection{Variables and data sources}

While our empirical specification accounts for state fixed effects, we try to account for various time varying and time invariant state or district level characteristics using existing information on the correlates of Covid19 contagion. However, given the novelty of COVID 19, our choice of correlates is not grounded in any theory. Most of the hypotheses, that are tested by other researchers, are either some ideas generated from our 
understanding of contagious diseases in general (e.g., contagion spreads faster in densely populated area) or some heuristics that originated from casual, empirical observations (e.g., COVID 19 spreads less in areas covered by BCG vaccination). For instance, the hypotheses regarding the Bacillus Calmette-Guérin (BCG) childhood vaccination has been tested by Miller et al.(Miller et al., 2020) and they found that countries without universal BCG vaccination such as Italy, Nederland and USA had been more severely affected by COVID 19 than the countries with universal BCG program, at least at the time they wrote the paper. There have been quite a few papers looking at the correlation between temperature and COVID infection which has been found to be negative (i.e. less contagion in high temperature areas) (Bannister-Tyrrell et al., 2020; Wang et al., 2020). However, there are papers which dispute this claim of a negative relationship between temperature and COVID infection. In one such paper, Zhu \& Xie (Zhu and Xie, 2020) studying the COVID situation in 122 cities across China, did not find any consistent negative relation between temperature and COVID infection.

Taking cue from the existing literature we use a rich set of covariates consisting of demographic, weather, economic and disease environment related variables. Under the demographic variables we consider population density. We control for weather variations using temperature, rainfall, latitude, and longitude. The variables that are considered under the economic category include levels of nightlight and unemployment. The disease environment variables include general immunization rate, BCG immunization rate and historical Malaria index.

We combine the Covid-19 database with information on these demographic, health, social, economic, geographic, and meteorological indicators from multiple sources for our analysis. While some of these indicators, including the information on Covid-19, are available at the district level, a few of our measures could only be obtained at the state level. Therefore, for the testing of our hypotheses we use the district level aggregated information where data is available. In some cases, where we are restricted to state level data, we use state level aggregation. Below we provide a detailed outline of all the supplementary data sources, and summarize each variable used in our analysis in Table 1.

\section{Table 1: Summary Statistics here}

\subsubsection{Demographic variables:}

The demographic variables that we use, include the population of a district and population density. The data come from the 2011 census. In the case of those districts that were created after 2011, we use the total population for the original district from the 2011 census and then distribute it in proportion to land area among the newly formed districts. The average population in a district is roughly 2.1 million. The average 
population per square $\mathrm{km}$ of a district is 601 , with a standard deviation more than double the value. We use the total population in a district to calculate our dependent variable, per capita infection rate in a district.

\subsubsection{Weather variables:}

The temperature and rainfall variables are obtained from the Indian Meteorological Department. Both variables are measured at the district level, on a daily basis. Hence, we are only able to use data from 2019 since real time weather data for 2020 is not freely available. The average temperature remains around 34 degrees Celsius. Mean rainfall is about $6.6 \mathrm{~mm}$ but with a very high variance across the districts of India.

\subsubsection{Health variables:}

We have discussed earlier that there are studies trying to link between the extent of the BCG vaccination program and the spread of COVID 19 outbreak. Accordingly, we have included the extent of BCG vaccination in Indian districts measured by the fraction of children in a district covered by BCG vaccination, as of 2007-2008, the earliest year for which we could find district level information on BCG vaccination. The data comes from District Level Household Survey (DLHS)-3, a nationally representative sample survey covering 720,000 households, that was conducted in 2007-08. There is another potential correlate that has been discussed in popular media - malaria prevalence. It was observed that COVID 19 infection is negatively related to malaria prevalence. Hence, we include information on prevalence of malaria across the districts of India, from the colonial period, as one of the independent variables in our regression framework. The data comes from (Cutler et al., 2010). This data provides a classification of districts according to its malaria intensity. There are 6 categories in total - categories 1 and 2 for non-malarious, 3 and 4 for potential epidemic, while 5 and 6 are classified as malarious.

\subsubsection{Measures of the regional inequality:}

\section{Nightlight inequality - state level}

Finally, we turn to our main variable of interest. We use nightlight data that measures the luminosity of night-time lights using satellite images. Specifically, we use the data from (Beyer et al., 2020). They extract the district level night-time light data from the VIIRS-DNB Cloud Free Monthly Composites (version 1) provided by the Earth Observation Group at Colorado School of Mines. While the monthly data would have allowed us to exploit more variation, the monthly nightlight data has a significant amount of noise (Beyer et al., 2020). Hence, we use the noise and outlier corrected lights averaged over a year, and standardized by the area in a district, used by (Beyer et al., 2021). The nightlights data is widely used as a proxy for economic activity (Prakash et al., 2019). We use the district level measure of luminosity in 2019 to create a state level inequality of luminosity. Specifically, we use the ratio of the highest $90 \%$ to the lowest $10 \%$ from the 
distribution of luminosity across districts within a state. We argue that the state level dispersion captures the degree of conglomeration in a state. In addition to the inequality measure, we also control for the level of nightlights in a district as a proxy for overall economic development.

\section{Nightlight inequality - district-neighbourhood level}

We use this measure to solve the problem of unobserved heterogeneity at the state level. Two districts are neighbours in our data if they share boundaries. This way, for each district there exists a cluster of districts which form its neighbourhood. We calculate the nightlight inequality for this neighbourhood which includes the district itself. A neighbourhood typically consist of 3-4 districts and therefore, our original measure of inequality - ratio of $90^{\text {th }}$ and $10^{\text {th }}$ percentile does not make much sense. Instead, we measure the disoersion of nightlight in the neighbourhood of a district in the following way:

$$
\eta_{d}=1-\frac{\mu_{M i n}^{d}}{\mu_{M a x}^{d}}
$$

In the above expression $\eta_{d}$ measures the neighbourhood nightlight inequality for district d. $\mu_{\text {Min }}^{d}$ is the minimum nightlight in the neighbourhood of district $\mathrm{d}$, while $\mu_{M a x}^{d}$ is the maximum value of nightlight in the same neighbourhood. This expression essentially becomes $R_{d} / \mu_{\text {Max }}^{d}$ where $R_{d}$ refers to the range (MaxMin) of nightlights across the district-neighbourhood. Range captures the degree of dispersion and therefore, higher the value of $\eta_{d}$, higher will be the value of neighbourhood inequality.

In Figure 5 we present the variation in nightlight-inequality across the districts of India. In this map, darker shades represent higher nightlight-inequality while the lighter spots represent low nightlight-inequality. ${ }^{6}$ The map reveals the structure of the regional inequality all across the country.

\section{Figure 5: A district level map of District-Neighborhood Nightlight-Inequality}

\section{Empirical Model}

In our empirical section we estimate how regional inequality along with the demographic, economic factors, weather, and disease environment influence the COVID 19 infection. The specific model we estimate for this purpose is the following:

$$
y_{d s t}=\beta_{0}+\beta_{1} N L I_{s}+\beta_{2} T_{t}+\beta_{3} X_{1 d s t}^{\prime}+\varepsilon_{d s t}
$$

\footnotetext{
${ }^{6}$ The bottom 10 percentile of the nightlight distribution is represented by the lightest shade. The top 10 percentile is represented by the 2 darkest shades.
} 
In the equation above, $\mathrm{y}_{\mathrm{dst}}$ captures the measure of contagion (number of confirmed Covid-19 cases per 1000 population) in district $\mathrm{d}$, state $\mathrm{s}$ and day $\mathrm{t}$. In our baseline model, $\mathrm{NLI}_{\mathrm{s}}$ represents nightlight inequality in state $s$ (the construction of this variable is discussed in section 3.2.4). $\mathrm{X}_{1 \mathrm{dst}}$ represents district, districttime and state-time varying controls. In our analysis, we have two variables that vary at district-time level temperature and rainfall. Most variables, such as latitude, population density, BCG vaccination, historical malaria intensity, nightlights, are recorded at the district level and do not vary with the days of 2020. We also include the extent of Covid tests conducted. It varies across states and with the days of 2020. $\beta_{1}$ is our parameter of interest. The variable $T$ measures the day of the year. We assign a value of 1 to the $1^{\text {st }}$ day of January 2020 and cumulatively calculate the number of days for each date in the 2020 calendar. This is our baseline specification. In section 5.2, we discuss the specification that uses district-neighborhood level of nightlight inequality along with state fixed effect.

\section{Results}

\subsection{State Level Regional Inequality and Covid-19 infection}

In Table 2 we report the estimates from equation (1), our baseline specification. Our main variable of interest is nightlight inequality and from our hypothesis, we expect that the effect of nightlight inequality on confirmed cases to be positive - the more unequal a state, the greater will be the movement between the core and the peripheral regions and higher will be the degree of Covid-19 contagion. In column 1, we regress total confirmed cases per 1 million population in a district on nightlight inequality at the state level. As expected, the coefficient for nightlight inequality is positive and significant.

\section{Table 2: State Level Nightlight Inequality and Covid-19 infection}

In column (2) we add factors that determine the number of confirmed cases mechanically. First, since the rate of infection is likely change over time, we include controls for time elapsed as days since January 1 , 2020. Second, the extent of urbanity or development of an area determines where the infection started spreading first. Hence, we include the average nightlight of a district before Covid-19 started, from 2019. Finally, the number of Covid-19 tests performed has also varied significantly across the states. We include daily Covid-19 tests performed. In columns 3-7 we include additional district level characteristics which are potential predictors of the number of cases per capita. In column (3) we add population density of the district, in column (4) we add a district's monthly temperature and rainfall information. In column (5) we add the extent of BCG and overall immunization, which includes tuberculosis, influenza etc., in a district. In column

(6) we add malaria intensity from historical data during the colonial period, and finally in column (7) we add controls for a district's latitude and longitude. 
We see that the coefficients for nightlight inequality are positive and significant across specifications implying that a state characterized by a stronger core-periphery structure, necessitating movement of goods and people between the core and the periphery, experience a greater rate of Covid-19 infection per capita. The number of tests conducted seems to be negatively correlated with the number of infections in columns 2 through 4 . This could simply reflect that those states with worse health investments have more cases and conduct fewer tests. Indeed, as a wider range of a state's health indicators are accounted for in columns 5-7, we find a positive correlation between Covid-19 tests and cases, as is likely to be the case mechanically since more tests will result in more detected cases.

The negative coefficients on the number of days elapsed since the beginning of the pandemic suggests that the average number of infections per capita fell over time. One reason this could happen is that after the initial first wave, there has been a secular decline in the Covid cases till 1st February 2021, the end date in our data, and the sub-periods of decline are dominating the aggregate situation. This idea becomes clearer when we show phase-wise results.

As expected, the coefficients for district level nightlights are also positive and significant across specifications implying that greater urbanization or economic development is correlated with a higher rate of infection. One counterintuitive finding is that the population density is negatively related with the total confirmed cases per 1000 population. One possibility is that more densely populated areas are more susceptible to Covid-19 outbreak and to prevent that governments usually impose stricter restrictions in these areas. This could explain the negative sign of the coefficient. ${ }^{7}$

In line with the popular belief, we find that daily infections rise with fall in temperature. The relationship between infection and rainfall, however, is positive. Contrary to popular beliefs, daily infections are higher in districts with greater levels of vaccination (BCG and overall). This result, however, is possibly driven by confounding variables. The BCG and other vaccination programs were possibly taken more vigorously in districts where the chance of epidemic is high due to several demographic and socio-economic variables. When a pandemic such as Covid-19 hits the country, these districts are more likely to be affected more. Therefore, the positive association between the rate of vaccination (BCG and other) in the past and Covid-

\footnotetext{
${ }^{7}$ The results from the heterogeneity analysis in Section 5.3 also point towards this possibility. During the strict lockdown phase, that was imposed country wide, the coefficient for population density is positive (Table 5, columns 1-2). However, as the economy opened up gradually during the unlock period, the coefficient on population density turned negative possibly due to stricter enforcement of 'micro-containment' zones in more dense regions (Table 5, columns 3-6).
} 
19 infection rate in the present could be driven by those confounding variables. The correlation between infection and malaria intensity is negative initially but after accounting for a district's latitude and longitude, turns positive. This points to the fact that the spread of malaria, at least during the colonial period, was limited to certain geographies. Within similar geographic areas, in terms of latitude and longitude, the regions that are historically more prone to malaria infection are also more prone to Covid-19 spread.

Overall, our results show that there exists a strong correlation between state level nightlight inequality and Covid-19 infection in spite of the staggered introduction of the covariates in Table 2. To put our results in context, Tan et al. (2021) found a positive association between county level income inequality and Covid19 infection and death in the United States. The nature of inequality and the mechanism discussed there, however, are different from our analysis. They found that the association between income inequality and Covid-19 infection nearly peaked during summer. They hypothesized that this was driven by poor people working in high risk, contact prone sectors such as hotels, restaurants and entertainment venues. Our result on the other hand, is driven by regional inequality in economic activity where mobility between the core and the periphery assumes a critical role. Nonetheless, identification remains a critical issue here as there are many unobserved heterogeneities at the state level that we could not account for as our main variable of interest - nightlight inequality - is time invariant and also measured at the state level. These unaccountedfor unobserved heterogeneities could also be the reason behind variability in the coefficients of the control variables across all the 7 specifications.

\subsection{Nightlight Inequality at District Neighborhood Level and Covid-19 infection}

To solve the identification problem in Table 2, we use regional inequality measured at the districtneighbourhood level. This allows us to take state-fixed effect which takes care of all unobserved heterogeneity at the state level. We also introduce state-time trends which takes care of any state specific heterogeneity that changes linearly with time. However, our identification rests on the assumption that no unobserved heterogeneity can exist at the district neighbourhood level. Even though policies are determined by the state governments, we cannot completely rule out differences across district neighbourhoods which could be correlated with the contagion. One such example can be local culture which may determine whether people abide by Covid regulations. We assume even if such culture exists and may affect the spread of Covid-19, it does not affect pre-Covid economic structure and nightlight inequality.

The idea behind this sub-state level measure of nightlight inequality is that a state might have multiple core regions and the movement of goods and people to various regions depends on which core serves which 
periphery. In other words, the extent of movement of people and goods might vary even within a state depending on the relative inequality of districts with respect to their neighbouring districts. We report the results from this estimation in Table 3. Equation 2 shows the estimation specification corresponding to Table 3 , where $\beta_{1}$ is the coefficient of interest.

$$
\begin{aligned}
& y_{d s t}=\beta_{0}+\beta_{1} N L_{d}+\beta_{2} \text { Days }_{t}+\beta_{3} N L_{d}+\beta_{4} \text { Test }_{s t}+\beta_{5} \text { Density }_{d}+ \\
& \beta_{6} \text { Temperature }_{d t}+\beta_{7} \text { Rainfall }_{d t}+\beta_{8} \text { BCG }_{d}+\beta_{9} \text { Vaccine }_{d}+\beta_{10} \text { Malaria }_{d}+ \\
& \beta_{11} \text { Latitude }_{d}+\beta_{12} \text { Longitude }_{d}+\text { Dummy }_{s}+\text { Dummy }_{s} * \text { Days }_{t}+\varepsilon_{d s t}
\end{aligned}
$$

\section{Table 3 Baseline regression with neighbourhood inequality}

In column 1, we regress total confirmed cases per 1million population on neighbourhood nightlight inequality with state fixed effect. The coefficient is positive and significant. From column 2 onwards, we keep adding controls in a staggered manner. Like in Table 2, the coefficients remain stable with the introduction of additional covariates, once over time changes in the contagion is accounted for in column 2. However, unlike in Table 2, after accounting for unobserved heterogeneity, the correlation between each of the control variables and confirmed cases remains the same across all specifications. In column 8 we account for state level linear time trends considering that different states experienced the first Covid-19 wave and their peak infection rates at different times. The effect of nightlight inequality remains unchanged with the staggered inclusion of all these covariates. We present the rest of our results in this paper on the basis of the full specification in column $8 .{ }^{8}$ Finally, for a district that is located at a state border, some of the neighbouring districts might belong to a different state. To account for this, we control for a border-district indicator. The results, reported in Appendix Table A6, show that the findings are similar to those in Table 3 although the estimates are larger in size. This is possibly due the strict mobility restrictions across state borders that were imposed during the lockdown period and continued for a long time in to the unlock periods (Irudaya Ranjan and Arokkiaraj, 2021). With mobility restrictions across states, the effect of neighborhood-nightlight inequality on Covid spread would be higher for districts where the neighboring region is entirely intra-state. Since the inter-state border restrictions varied over time and across space, we use the more conservative estimates that allow the effect of regional inequality on Covid-19 to also depend on inter-state movement, as our main specification.

\footnotetext{
${ }^{8}$ As observed in Figures 2 and 3, confirmed cases evolve non-linearly over time. To account for this, we introduced non-linear time effects in our model. The results, presented in Appendix Table A5, remain unchanged.
} 


\subsection{Heterogeneity Analysis}

In response to the COVID 19 pandemic, the government of India, in March 2020, announced a lockdown resulting in the suspension of usual activities of government offices, business establishments and educational institutions - everything except those related to the supply of essential goods and services. ${ }^{9}$ Subsequently, over different phases of lockdown (and eventually unlocks), different types of activities were allowed. This set of policies, popularly known as lockdown, varied in their intensity over time - they were relaxed or tightened depending on the Covid-19 situation in India. The details of the lockdown and unlock phases are given in Table 4.

\section{Table 4 Phases of lockdown}

Our hypothesis, that the core-periphery structure of the economy can affect the rate of infection transmission, rests on the premise that it involves movement of people between the core and the periphery. The different phases of lockdown and unlock led to different degrees of movements of people and vehicles. Hence, we expect that the effect of the core-periphery structure (as measured by regional inequality of nightlights) on the contagion would depend on the restrictions imposed on the movement of goods and people across different phases of lockdown and unlock, in the first place. Accordingly, we check how the relationship between Covid-19 infection rate and regional inequality changes across different phases of lockdown and unlock.

For brevity, we do not report our result for all the phases of lockdown and unlock. In Table 5 we report the results for 4-17 May, 2020 (lockdown 3), 18-31 May, 2020 (lockdown 4), September 2020 (unlock 4) and October, 2020 (unlock 5), November 2020 (unlock 6) and December, 2020 (unlock 7). We have reported the results for lockdown 3 and 4, because these are the phases of lockdown when the restrictions on movements of goods and people started to relax. On the other hand, unlock 4 onwards, the restrictions were lifted to a great extent and almost free movements were allowed across the states.

\section{Table 5 Neighbourhood inequality and Covid infection rate for phases of lockdown and unlock}

We find that nightlight inequality in a district's neighborhood has no effect on the spread of the disease during Lockdown 3 when the stringent movement restrictions were just beginning to be eased. During this phase, districts were categorized into red, orange and green zones on the basis of the severity in the spread of infection and some relaxations were allowed in districts that had lowest severity (i.e. green zone) at that time. During lockdown 3, such categorization was determined at the central government level. During Lockdown 4, the states were given a larger say in the demarcation of districts into red, orange and green

\footnotetext{
${ }^{9}$ The list of essential goods was defined at the beginning of the Lockdown in March. Appendix Table A2 and A3 provides details on the various restrictions across lockdown and unlock phases and the essential goods, respectively.
} 
zones. With better local information state level administrations are likely to better identify districts that are potentially at a higher risk of contagion. For instance, local governments are better able to identify regions that are economically more active. Knowing that economic development of a region and infection rates are directly proportional, it is possible that state governments grant fewer lockdown relaxations to the more economically active districts (the core), within a state, than the less economically active districts (the periphery). This would make movement from the core district to the peripheral districts, within a state, more difficult. Indeed, this is evident from the negative significant coefficient on the average nightlight in a district in column 2 of Table 5. A district with higher levels of nightlights, indicating more development, also have fewer cases during lockdown.

It is easier to see this using an example. Consider two distinct clusters of districts: high inequality cluster (H) and low inequality Cluster (L) within a state. For example, in the state of West Bengal, $\mathrm{H}$ cluster has Kolkata (West Bengal's capital and one of the biggest cities in India) as the core district and L cluster has North Dinajpur (a northern district) as the core district. Between these two clusters, Kolkata is economically more active than North Dinajpur. Kolkata is also associated with much higher neighbourhood nightlight inequality compared to North Dinajpur -- the neighbourhood nightlight inequality for Kolkata is 0.98 and that for North Dinajpur is 0.66 . We expect lockdown stringency, administered by the states, to be higher for districts with more active areas (higher inequality) than for districts with less active areas(lower inequality). In our example, we expect that the stringency of lockdown measures will be much higher in Kolkata than that in North Dinajpur. This was indeed the case during the third and fourth phases of lockdown; while Kolkata was categorized as red zone, North Dinajpur was categorized as green zone ${ }^{10}$. This in turn means that the disease would spread faster in cluster L, where the economic distance between the core (North Dinajpur) and the periphery is lower, than in cluster $\mathrm{H}$, where the distance between the core (Kolkata) and the periphery is higher and lockdown restriction higher. This could potentially explain the negative coefficient on both the neighbourhood inequality and average nightlight measures during the Lockdown periods.

Columns (3)-(6) of Table 5 show the results for the unlock phases. The withdrawal of lockdown measures is instrumental for the mechanism underlying our main result to hold. During the early phases of unlock (June-August, 2020), restrictions were being withdrawn in phased manner with night curfews in place for most of these phases. Several states, particularly the ones with metropolitan cities, like Maharashtra, Tamil

\footnotetext{
${ }^{10} \mathrm{https}$ //www.news18.com/news/india/centre-marks-all-metro-city-as-red-zones-for-covid-19-curbs-post-may-3-heres-the-fulllist-2600595.html
} 
Nadu and West Bengal, continued with restrictive measures on all or a few days of the week. Restrictions on public transportation continued in most states during this period. From September 2020 onwards, however, movements of goods and people were coming back to normal and we find a strong positive, significant relationship between nightlight inequality and Covid-19 infection for the entire period between September 2020 and December 2020. Overall, we find that the relationship between nightlight inequality and Covid-19 spread holds only for the phases of unlock when movement restrictions were significantly relaxed pointing to the underlying mobility mechanism.

\subsection{Mechanism and Robustness}

\subsubsection{Nightlight Inequality and Mobility}

In understanding the effect of nightlight inequality on Covid-19 infection, we argued that the underlying mechanism is mobility of goods and people. If all the business establishments and transportation are shut down, there should not be much of a difference between equal and unequal regions in terms of the spread of the disease. In the previous section, we provided indirect evidence of this mechanism by using the lockdownunlock phases. In this section we provide more direct evidence using mobility information from Facebook Data for Good ${ }^{11}$. In this data, the geographical space has been divided into polygons. The size of a polygon is 600 meters by 600 meters at the equator which changes as we move towards the poles. Facebook records the start and end polygon of everyone with a Facebook application installed on their smartphone from GPS location of the phone. Using this information, Facebook mobility data then computes distance travelled. The database also provides the corresponding administrative unit for the start and end points (Using the United States as an example, level 1 is US, level 2 is Florida, Level 3 is Dade County, level 4 is Miami. For India, level 3 is district).

Thus, the data from Facebook only includes the mobility information of people with smartphones with the Facebook application and phone GPS turned on. In addition, it does not include data from a geographical unit if there are less than 10 movements in a day. Consequently, not all the districts are covered in the Facebook database. Furthermore, this means that the Facebook data represents mobility for a small fraction of the population. Nevertheless, some studies have shown that the aggregate district level mobility numbers from the Facebook data corresponds with migration reported in the Census data and hence provides a useful proxy of the overall mobility (Chadha and Raghu, 2021).

\footnotetext{
${ }^{11}$ We access this data from "Facebook Data for Good" (https://dataforgood.facebook.com/).
} 
We argue that unequal regions are characterized by greater mobility which in turn leads to greater Covid infection. In Table 6, we present the estimates of the effect of neighborhood inequality on mobility. Using the Facebook Mobility data, we measure mobility as number of people moving within and across districts. In column (1) we regress mobility on neighbourhood inequality without any control and find that the coefficient is positive and significant, implying that higher nightlight inequality in the neighbourhood of a district reflects greater degree of movement both within the district, as well as to and from that district. From column (2) to (5), we keep adding controls like the ones used in the baseline regression in Table 3. In column (2) we account for the average nightlight of a district to capture the overall level of activity. The strong positive coefficient confirms our prior that a high level of economic activity is associated with a high degree of mobility. In addition, the negative coefficients on the number of days (since $1^{\text {st }}$ January 2020 ) and on the number of daily covid tests indicate that overall mobility went down as covid cases rose. The effect-size of neighborhood inequality on mobility remains unaltered by the addition of further controls in columns (3) through (5). Overall, we find that nightlight inequality remains a strong predictor of mobility measured from the Facebook data.

\section{Table 6: Nightlight inequality and mobility here}

\subsubsection{Mobility as the underlying mechanism}

While the results in Table 6 show the first-stage relationship that we implicitly assumed in Table 3, we turn to a direct investigation of the extent to which the relationship between neighborhood nightlight inequality and spread of the contagion is indeed driven by mobility across districts. Specifically, if mobility is the main channel through which nightlight inequality is driving the spread of Covid, then controlling for mobility in Table 3 should temper the effect of nightlight inequality on Covid-19 spread. ${ }^{12}$ In Table 7, we provide evidence on this potential mechanism. In column (1) we replicate the baseline specification that we used in column (8) of Table 3. In column (2) of Table 7, we add mobility as a control along with other controls used in baseline specification. We find that mobility has a positive and significant effect on Covid-19 infection but the coefficient for nightlight inequality is not significant anymore. This provides direct support for our

\footnotetext{
${ }^{12}$ In an alternative analysis we also use district level industrial heterogeneity to proxy for mobility of and higher social interaction among people. Our measure of industrial heterogeneity $\left(h_{d}\right)$ uses the share of labor force in different industries $\left(h_{d}=1-\sum_{i} s_{i d}^{2}\right.$, where $s_{i d}$ is the share of workforce in industry $i$ in district $d$ ). The underlying thought is that, in a district with higher industrial heterogeneity people from the same family are more likely to work in different industries. Hence if a person gets infected from her workplace, there is a higher chance of spread to other industries through her family members who work there. Since industrial heterogeneity is measured at the district level, we account for state fixed effects in these specifications. The estimates are in line with our main findings. Industrial heterogeneity has no effect on the contagion during the Lockdown phases. However, as the industries open up and mobility increases, we find a positive effect of industrial heterogeneity on the spread of Covid-19. These results are reported in Appendix Tables A6 and A7. However, due to data limitations, we are unable to establish our claim to the mechanism that higher industrial heterogeneity reflects greater diversity in employment within the same household. Hence, we cannot be sure that industrial heterogeneity is indeed capturing a greater extent of social interactions. Hence, we refrain from reporting these findings as part of our main analysis.
} 
proposed mechanism. More unequal regions are characterized by greater movements of goods and services between the core and the periphery which in turn leads to greater spread of the disease. Consequently, once we take control of the mobility, the coefficient for nightlight inequality becomes insignificant.

\section{Table 7: Covid 19 infection, nightlight inequality and mobility}

\subsubsection{Unemployment and mobility}

While the result in panel A of Table 7 strongly indicates that the effect of nightlight inequality on the contagion works through mobility, there are limitations of the Facebook Mobility data in terms of its representativeness. Hence, in this section, we further investigate the mechanism using state-level daily unemployment rates as a proxy for mobility. ${ }^{13}$ We argue that traveling to work depends on employment status. Specifically, mobility is driven by the employed and regions with higher levels of unemployment would experience lower levels of mobility. Indeed, we see this relationship in our data. Appendix Table A4 shows the relationship between state-level daily unemployment rates and mobility patterns. We conduct this analysis for the unlock phases considering that mobility was restricted due to government regulations during the lockdown period. The negative estimates imply that both inter-district and within-district mobility were significantly low in states with high unemployment rates. Hence, we expect that when unemployment rate is high, the effect of nightlight inequality on Covid infection rate will be low since the mobility effect will be muted. Accordingly, we regress district level daily per capita infection spread on the interaction of state level nightlight inequality and state level daily unemployment rate. In contrast to Table 2 , this specification also allows us to introduce state fixed effects and state level time trends to account for all other state level factors that might affect the spread of Covid-19, that are either fixed over time or vary linearly over time. Otherwise, the specification that we use is comparable to Table 2 except that we now introduce daily unemployment rate and the interaction of state-nightlight inequality with unemployment rate. We expect the interaction effect of nightlight inequality and unemployment rate to be negative. Between two states with different levels of nightlight inequality, the spread of Covid-19 is expected to be lower in the states with higher levels of unemployment. We present the results in panel B of Table 7.

Column (1) presents the iteration-specification without any fixed effects. We find that nightlight inequality has a positive effect on contagion, as before. Also, states with higher unemployment rate have lower levels of contagion, after accounting for economic development proxied by average levels of nightlight. The interaction between nightlight inequality and unemployment is significantly negative. Together these results imply that the positive effect of the inequality on infection is partially mitigated in states whenever the

\footnotetext{
${ }^{13}$ We interpolate the daily unemployment rate using the monthly unemployment rate published by Centre for Monitoring Indian Economy (CMIE)
} 
movements are less (i.e. unemployment is high). These results remain similar across the four different specifications. In column 2 we introduce state level linear time trends. In column (3) we account for unobserved heterogeneity at the state level and in column (4) we introduce both state fixed effects and state level linear time trends - the interaction effect remains unaltered.

\section{Appendix Table A4: Mobility and Unemployment during unlock phases}

\section{Conclusion}

The growing literature studying the factors that contribute to Covid-19 spread focuses on demographic, social, weather and health related indicators. We provide an additional explanation based on mobility which we capture using measures of regional inequality. The underlying logic of our empirical strategy is based on economic-geography theories which suggest that the organization of economic activities often follows a core-periphery pattern within a region thereby creating regional inequality. Higher dependence of the peripheral areas on the core may lead to greater movements of goods and people in such a region. In the event of an outbreak, one may therefore logically expect greater spread of infection through such movements in areas characterized by greater regional inequality. Using data from the first year (April, 2020 - February, 2021) of the Covid-19 contagion across the various districts of India we find that Covid-19 spreads more in regions characterized by a greater degree of inequality in economic activity. We measure regional inequality in economic activity using inequality in the incidence of nightlights across districts.

Our empirical findings show that regions with higher nightlight inequality experience higher spread of Covid-19. Using Facebook mobility data, we find support for the underlying mechanism - that much of the effect of nightlight inequality on the spread of Covid is explained by movement of people. Further, when we conduct the exercise over different phases of lockdown and unlock, imposed by the Government of India, we find that regions with higher nightlight inequality experience higher spread of Covid-19 only when lockdown measures have been relaxed and movement of people are near normal.

Our findings provide a potential ex-ante selection criterion for prioritizing anti-Covid policies. During the first year of Covid-19, the policy responses to Covid-19 contagion, in India and across the world, relied mostly on the lockdown strategy and for the most part of the year it was homogeneous across India --- one policy for the entire nation. However, such a stringent lockdown possibly came at a very high cost. Numerous media and policy documents report the economic loss during lockdown. An estimate published in April 2021 by the State Bank of India show that total economic loss is roughly INR 1.5 trillion (approximately 20 Billion 
USD). ${ }^{14}$ Besides economic loss, the first two phases of lockdown in India saw an unprecedented humanitarian crisis in the plight of the migrant workers ${ }^{15}$. A large part of this crisis had its root in the initial stringent lockdown which was imposed uniformly across India.

One suggestion that comes out of our research is the selective policy implementation based on regional inequality in economic activity; more intense implementation of the policy instrument only in areas characterised by greater nightlight inequality. The idea of selective policy implementation is not entirely novel when it comes to lockdown strategies. We have seen that during the unlock phases, the Indian government has followed this strategy based on the number of confirmed cases in an area. Essentially, under this policy, the districts were categorized into various color-coded zones based on the severity of the contagion and the stringency of the lockdown imposed varied accordingly. But this categorization was done based on the number of confirmed cases which was revealed ex-post. Our suggested strategy is based on an ex-ante measure, regional nightlights inequality, that has potential to predict the prospective severity of the contagion in different regions even before the spread of the contagion. Therefore, while government strategy only works after an area is severely affected, our suggested approach can be deployed before the contagion spreads and can be used to minimize economic and human loss. With vaccine's inclusion to the array of antiCovid policy instruments, we can apply the basic principle of our policy suggestion and prioritize areas for vaccination drive based on the structure of regional inequality.

However, there are a few important caveats that must be noted while considering this approach. First, we must emphasize that while we have controlled for a wide range of covarying factors at the district level that could drive our results, it is not possible to rule out unobserved heterogeneity completely. In the absence of strict exogeneity conditions, we must exercise caution in interpreting the results of our paper causally. Hence, our policy recommendations are only suggestive based on our empirical findings.

Second, the underlying mechanism of our results is mobility and at least in the case of India, we find that mobility is correlated with regional inequality in economic activity captured by nightlight inequality. However, this relationship between mobility and regional inequality is likely to depend on institutional and technological factors and whether this result is generalizable to other countries is an empirical question and cannot be answered without looking into data from other countries.

\footnotetext{
${ }^{14} \mathrm{https}$ //www.business-standard.com/article/economy-policy/economic-cost-of-mobility-curbs-lockdowns-at-rs-1-5-trillion-sbireport-121042300326_1.html

15 https:/www.bbc.com/news/av/world-asia-52776442
} 
Finally, stringent lockdown in unequal regions may have a severe negative impact on the poor if the poor are more likely to live in more unequal regions. Even though existing research suggests that regions characterized by high degree of regional inequality are necessarily not the poorer ones (Mveyange, 2015; Singhal et al., 2020) we cannot rule out this possibility completely. Nevertheless, in the event of a stringent lockdown in unequal regions, we can think of a redistributive policy which would transfer resources from the rich core to the poor periphery to support the poor people in the peripheries. It is also worth noting that the alternative to our selective lockdown is the blanket lockdown. The blanket lockdown impacts both equal and unequal regions alike and, therefore, is Pareto inferior to the policy of selective lockdown. Moreover, it is important to note that the essence of our policy suggestion is selective policy implementation, and it is not limited to lockdown measures. The principle suggested by our research is applicable to other anti-Covid measures such as vaccination. 
References:

Bannister-Tyrrell, M., Meyer, A., Faverjon, C., Cameron, A., 2020. Preliminary evidence that higher temperatures are associated with lower incidence of COVID-19, for cases reported globally up to 29th February 2020. medRxiv.

Beyer, R., Jain, T., Sinha, S., 2020. Lights Out? COVID-19 Containment Policies and Economic Activity.

Beyer, R.C.M., Franco-Bedoya, S., Galdo, V., 2021. Examining the economic impact of COVID-19 in India through daily electricity consumption and nighttime light intensity. World Development 140, 105287.

Bonacini, L., Gallo, G., Patriarca, F., 2021a. Identifying policy challenges of COVID-19 in hardly reliable data and judging the success of lockdown measures. Journal of Population Economics 34, 275-301.

Bonacini, L., Gallo, G., Scicchitano, S., 2021b. Working from home and income inequality: risks of a 'new normal' with COVID-19. J Popul Econ 34, 303-360. https://doi.org/10.1007/s00148-020-00800-7

Brunnermeier, M.K., 2021. The Resilient Society. Endeavor Literary Press.

Burkhauser, R.V., Feng, S., Jenkins, S.P., 2009. Using the P90/P10 Index to Measure U.s. Inequality Trends with Current Population Survey Data: A View from Inside the Census Bureau Vaults. Review of Income and Wealth 55, 166-185. https://doi.org/10.1111/j.1475-4991.2008.00305.x

Chadha, N., Raghu, S., 2021. Measuring migration-related movements from daily mobility data (No. 2021/1), India Development Foundation Working Paper.

Chiplunkar, G., Das, S., 2021. Political institutions and policy responses during a crisis. Journal of Economic Behavior \& Organization 185, 647-670. https://doi.org/10.1016/j.jebo.2021.03.018

Cutler, D., Fung, W., Kremer, M., Singhal, M., Vogl, T., 2010. Early-life malaria exposure and adult outcomes: Evidence from malaria eradication in india. American Economic Journal: Applied Economics 2, 72-94. https://doi.org/10.1257/app.2.2.72

Henderson, J.V., Storeygard, A., Weil, D.N., 2012. Measuring economic growth from outer space. American economic review 102, 994-1028.

Irudaya Ranjan, S., Arokkiaraj, H., 2021. Travel restrictions and mobility amidst COVID curfew in India [WWW Document]. The Mobility Technology and Wellbeing Lab. URL https://www.eth.mpg.de/molab-inventory/shock-immobilities/travel-restrictions-and-mobilityamidst-covid-curfew-in-india (accessed 6.16.22).

Kijima, Y., 2006. Why did wage inequality increase? Evidence from urban India 1983-99. Journal of Development Economics 81, 97-117. https://doi.org/10.1016/j.jdeveco.2005.04.008

Milani, F., 2021. COVID-19 outbreak, social response, and early economic effects: a global VAR analysis of cross-country interdependencies. Journal of population economics 34, $223-252$.

Miller, A., Reandelar, M.J., Fasciglione, K., Roumenova, V., Li, Y., Otazu, G.H., 2020. Correlation between universal BCG vaccination policy and reduced morbidity and mortality for COVID-19: an epidemiological study. MedRxiv.

Mveyange, A., 2015. Night lights and regional income inequality in Africa. WIDER Working Paper.

Piketty, T., 2014. Capital in the twenty-first century. Cambridge Massachusetts : The Belknap Press of Harvard University Press, 2014.

Prakash, A., Shukla, A.K., Bhowmick, C., Beyer, R.C.M., 2019. Night-time luminosity: Does it brighten understanding of economic activity in India. Reserve Bank of India Occasional Papers 40.

Qiu, Y., Chen, X., Shi, W., 2020. Impacts of social and economic factors on the transmission of coronavirus disease 2019 (COVID-19) in China. Journal of Population Economics 33, 1127-1172.

Rodríguez-Pose, A., Tselios, V., 2011. Mapping the European regional educational distribution. European Urban and Regional Studies 18, 358-374. https://doi.org/10.1177/0969776411399345

Rodríguez-Pose, A., Tselios, V., Winkler, D., Farole, T., 2013. Geography and the Determinants of Firm Exports in Indonesia. World Development 44, 225-240.

https://doi.org/10.1016/j.worlddev.2012.12.002 
Singhal, A., Sahu, S., Chattopadhyay, S., Mukherjee, A., Bhanja, S.N., 2020. Using night time lights to find regional inequality in India and its relationship with economic development. PloS one 15, e0241907.

Tan, A.X., Hinman, J.A., Abdel Magid, H.S., Nelson, L.M., Odden, M.C., 2021. Association Between Income Inequality and County-Level COVID-19 Cases and Deaths in the US. JAMA Network Open 4, e218799. https://doi.org/10.1001/jamanetworkopen.2021.8799

Tselios, V., Stathakis, D., 2020. Exploring regional and urban clusters and patterns in Europe using satellite observed lighting. Environment and Planning B: Urban Analytics and City Science 47, 553-568. https://doi.org/10.1177/2399808318788567

Wang, J., Tang, K., Feng, K., Lv, W., 2020. High temperature and high humidity reduce the transmission of COVID-19. Available at SSRN 3551767.

Zhu, Y., Xie, J., 2020. Association between ambient temperature and COVID-19 infection in 122 cities from China. Science of the Total Environment 138201. 


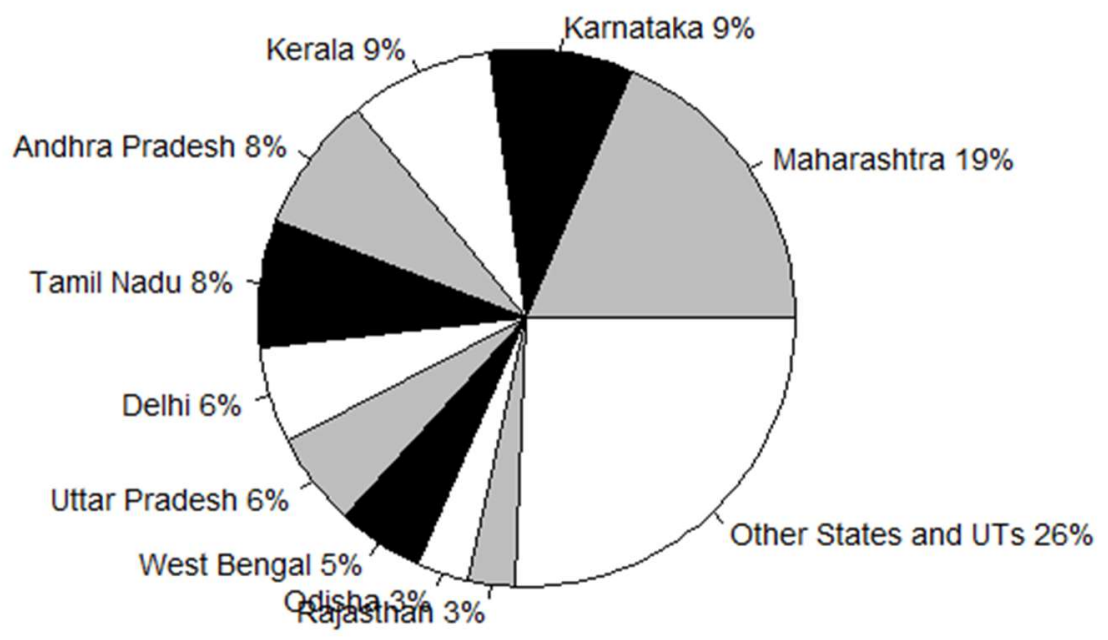

Figure 1: Share of Covid-19 confirmed cases in 10 leading states

Notes: The figure plots fraction of total cumulative confirmed cases of Covid-19 on Feb 1, 2021, for 10 top states in terms of total covid infection 

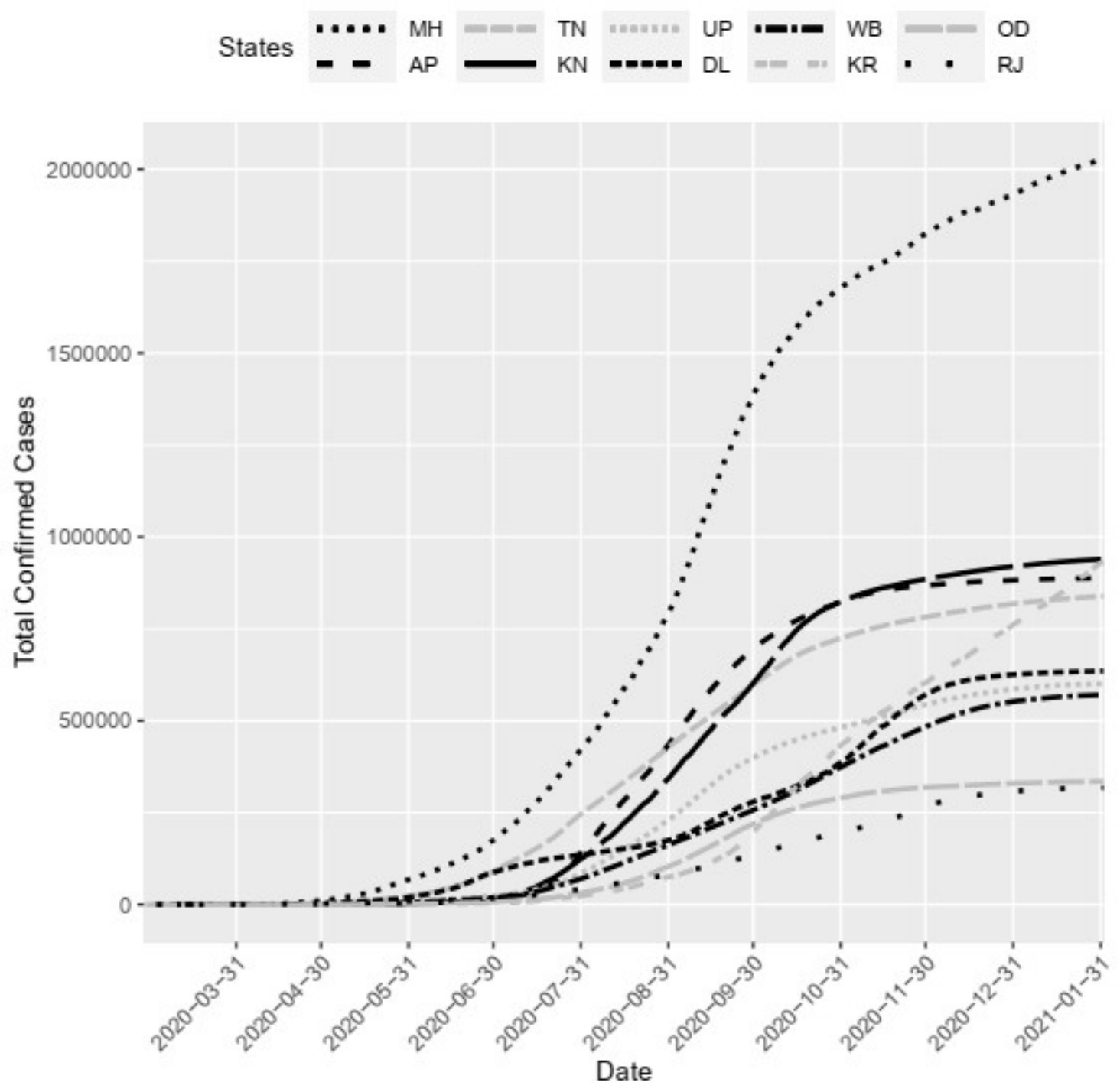

Figure 2: Covid-10 confirmed cases in 10 leading states

Notes: The figure plots cumulative values of confirmed cases of Covid-19 over the period, Jan 1, 2020 - Feb 1,2021 


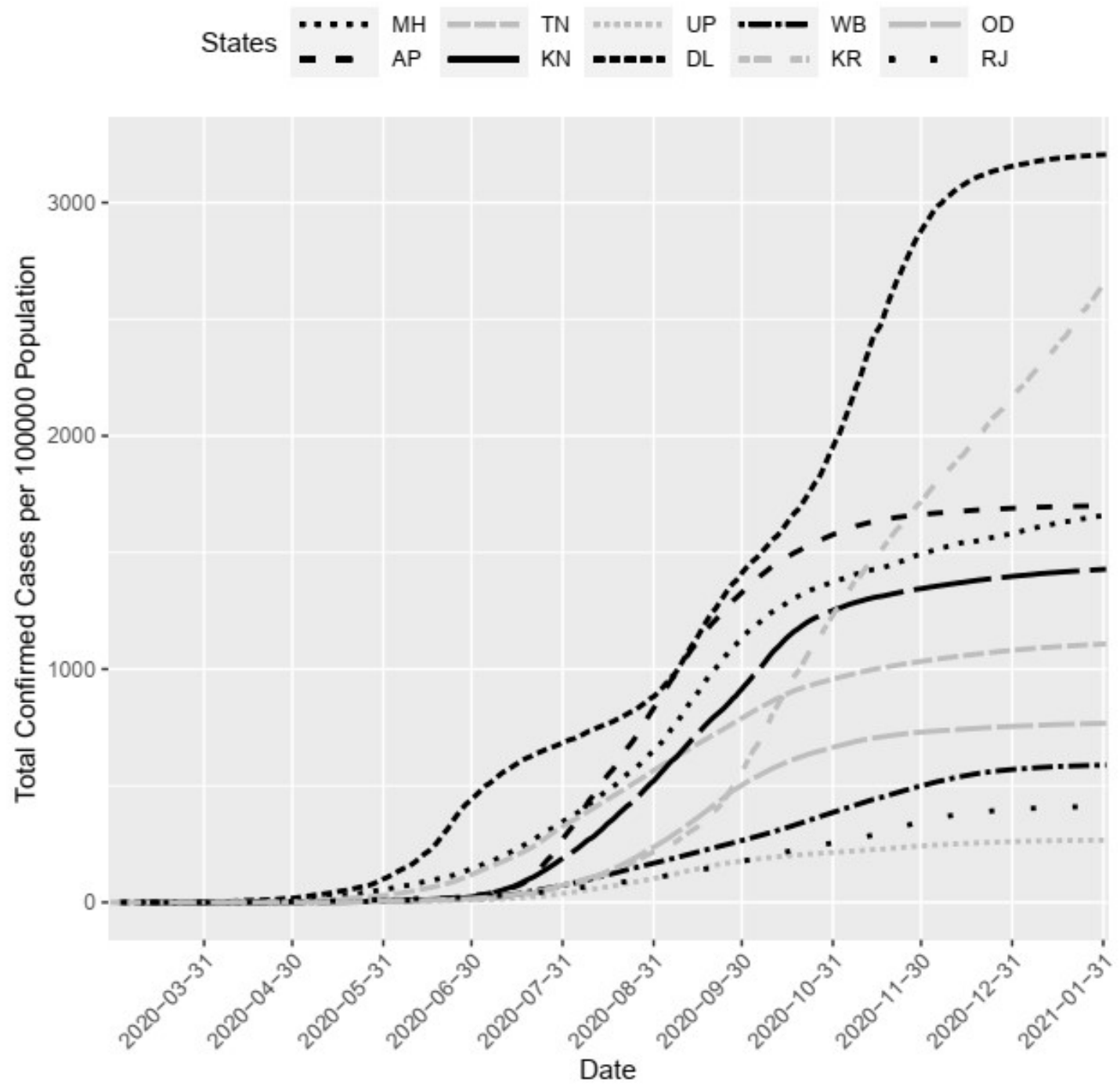

Figure 3: Covid-10 confirmed cases per 100 thousand population in 10 leading states

Notes: The figure plots cumulative values of confirmed cases of Covid-19, as a fraction of total state population, over the period, Jan 1, 2020 - Feb 1, 2021 


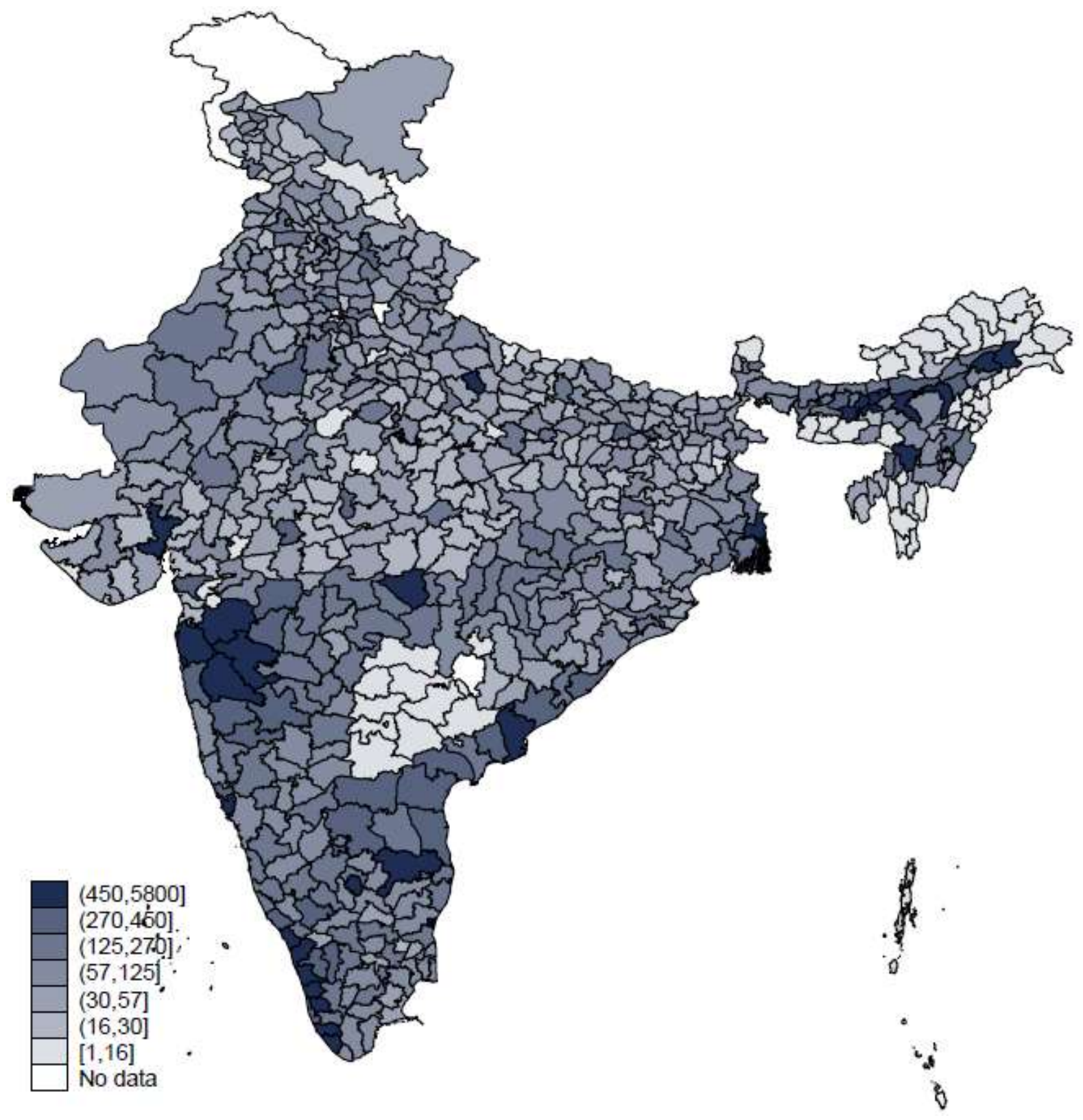

Figure 4: A district level map of daily confirmed cases

Notes: The map plots average of daily confirmed cases in a district over the period of our regression analysis, May 4, 2020 - Feb 1, 2021 


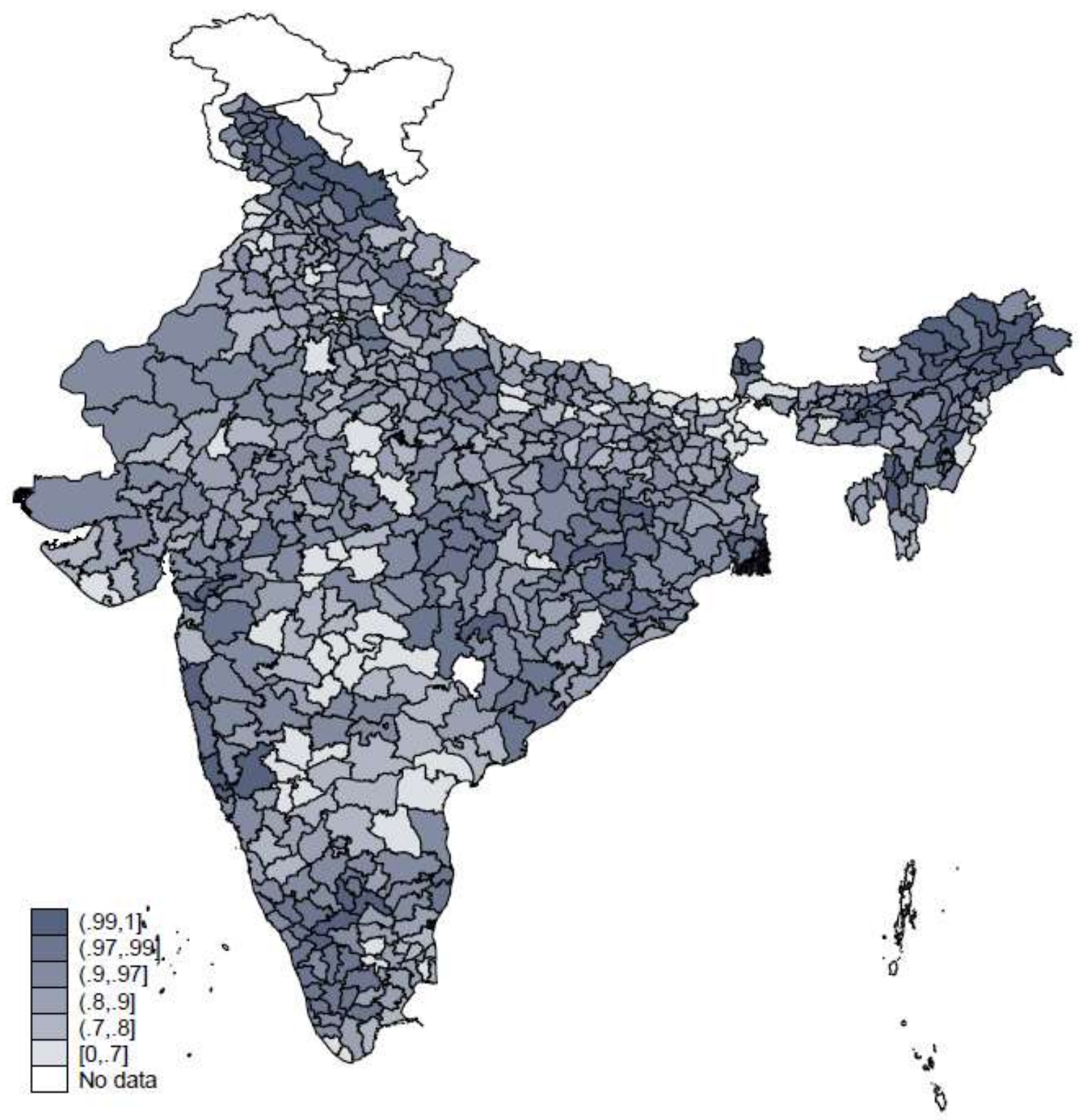

Figure 5: A district level map of District-Neighborhood Nightlight-Inequality

Notes: The map plots nightlight-inequality for every district ( $\eta_{d}$, as defined in Section 3.2.4), over the period of our regression analysis, May 4, 2020 - Feb 1, 2021. 


\begin{tabular}{lllll}
\hline Variables & Mean & SD & 10 Percentile & 90 Percentile \\
\hline Confirmed per million & 8857 & 5570 & 3154 & 17049 \\
District Population (million) & 2.15 & 1.53 & 0.67 & 4.05 \\
Nightlight (district level) & 4.62 & 14.13 & 0.49 & 8.65 \\
Nightlight Inequality [p90/p10] & 2.44 & 1.02 & 1.03 & 3.89 \\
District Population Density, 2019 & 735 & 3680 & 157 & 1099 \\
Temperature (Celsius) & 31.08 & 6.07 & 23.79 & 38.91 \\
Rainfall (mm) & 4.34 & 13.48 & 0.00 & 12.56 \\
Malaria & 4.86 & 1.26 & 3.00 & 6.00 \\
Latitude (N) & 23.04 & 5.98 & 12.81 & 30.28 \\
Longitude (E) & 79.09 & 4.44 & 74.12 & 85.99 \\
\% BCG Vaccination, 2007 & 87.76 & 11.20 & 72.30 & 98.90 \\
\% Fully Immunized, 2007 & 56.08 & 21.44 & 25.60 & 83.60 \\
Observations & 139309 & 139309 & 139309 & 139309 \\
\hline Table 1: Summary Statistics, Regression Sample & & &
\end{tabular}




\begin{tabular}{|c|c|c|c|c|c|c|c|}
\hline \multicolumn{8}{|c|}{ Dependent Variable: Total Confirmed Covid19 per million population } \\
\hline & $(1)$ & $(2)$ & (3) & (4) & $(5)$ & (6) & (7) \\
\hline \multirow{2}{*}{$\begin{array}{l}\text { Nightlight } \\
\text { Inequality }\end{array}$} & $6.528 * * *$ & $6.012 * * *$ & $6.000 * * *$ & $5.648 * * *$ & $3.347 * * *$ & $3.452 * * *$ & $3.755^{* * *}$ \\
\hline & $(0.177)$ & $(0.178)$ & $(0.178)$ & $(0.180)$ & $(0.180)$ & $(0.183)$ & $(0.182)$ \\
\hline \multirow[t]{2}{*}{$\begin{array}{l}\text { Days since } \\
\text { Jan1. } 2020\end{array}$} & & $-0.012 * * *$ & $-0.013 * * *$ & $-0.038 * * *$ & $-0.071 * * *$ & $-0.074 * * *$ & $-0.084 * * *$ \\
\hline & & $(0.003)$ & $(0.003)$ & $(0.004)$ & $(0.004)$ & $(0.004)$ & $(0.004)$ \\
\hline \multirow[t]{2}{*}{$\begin{array}{l}\text { Nightlight } \\
\text { (average) }\end{array}$} & & $0.476^{* * *}$ & $0.598 * * *$ & $0.611 * * *$ & $0.567 * * *$ & $0.575 * * *$ & $0.614 * * *$ \\
\hline & & $(0.012)$ & $(0.017)$ & $(0.017)$ & $(0.017)$ & $(0.017)$ & $(0.017)$ \\
\hline Daily tested & & $\begin{array}{c}-0.024 * * * \\
(0.005)\end{array}$ & $\begin{array}{c}-0.023^{* * *} \\
(0.005)\end{array}$ & $\begin{array}{c}-0.021 * * * \\
(0.005)\end{array}$ & $\begin{array}{c}0.075^{* * *} \\
(0.005)\end{array}$ & $\begin{array}{c}0.094^{* * *} \\
(0.005)\end{array}$ & $\begin{array}{c}0.086 * * * \\
(0.005)\end{array}$ \\
\hline $\begin{array}{l}\text { Population } \\
\text { density }\end{array}$ & & & $\begin{array}{c}-0.664 * * * \\
(0.066)\end{array}$ & $\begin{array}{c}-0.749 * * * \\
(0.067)\end{array}$ & $\begin{array}{c}-0.770 * * * \\
(0.065)\end{array}$ & $\begin{array}{c}-0.757 * * * \\
(0.064)\end{array}$ & $\begin{array}{c}-0.841 * * * \\
(0.064)\end{array}$ \\
\hline Temperature & & & & $\begin{array}{c}-0.529 * * * \\
(0.047)\end{array}$ & $\begin{array}{c}-0.570 * * * \\
(0.046)\end{array}$ & $\begin{array}{c}-0.540 * * * \\
(0.046)\end{array}$ & $\begin{array}{c}-0.750 * * * \\
(0.048)\end{array}$ \\
\hline Rainfall & & & & $\begin{array}{c}0.332 * * * \\
(0.014)\end{array}$ & $\begin{array}{c}0.281 * * * \\
(0.014)\end{array}$ & $\begin{array}{c}0.263 * * * \\
(0.014)\end{array}$ & $\begin{array}{c}0.241 * * * \\
(0.014)\end{array}$ \\
\hline \multirow[t]{2}{*}{$\begin{array}{l}\mathrm{BCG} \\
\text { vaccination }\end{array}$} & & & & & $0.695 * * *$ & $0.684 * * *$ & $0.565^{* * *}$ \\
\hline & & & & & $(0.029)$ & $(0.030)$ & $(0.030)$ \\
\hline \multirow[t]{2}{*}{$\begin{array}{l}\text { Total } \\
\text { vaccination }\end{array}$} & & & & & $0.258 * * *$ & $0.265 * * *$ & $0.213 * * *$ \\
\hline & & & & & $(0.016)$ & $(0.016)$ & $(0.016)$ \\
\hline \multirow[t]{2}{*}{$\begin{array}{l}\text { Colonial } \\
\text { malaria }\end{array}$} & & & & & & $-0.620 * * *$ & $0.663 * * *$ \\
\hline & & & & & & $(0.145)$ & $(0.165)$ \\
\hline Latitude & & & & & & & $\begin{array}{c}-0.604 * * * \\
(0.034)\end{array}$ \\
\hline Longitude & & & & & & & $\begin{array}{c}-1.013 * * * \\
(0.046)\end{array}$ \\
\hline Constant & $\begin{array}{c}18.177 * * * \\
(0.469)\end{array}$ & $\begin{array}{c}21.518 * * * \\
(0.756)\end{array}$ & $\begin{array}{c}21.532 * * * \\
(0.755)\end{array}$ & $\begin{array}{c}43.638 * * * \\
(2.389)\end{array}$ & $\begin{array}{c}-20.383 * * * \\
(2.990)\end{array}$ & $\begin{array}{c}-18.917 * * * \\
(3.012)\end{array}$ & $\begin{array}{c}91.007 * * * \\
(4.828)\end{array}$ \\
\hline Observations & 148,737 & 147,875 & 147,875 & 147,473 & 145,640 & 139,309 & 139,309 \\
\hline $\begin{array}{l}\text { Adjusted } \\
\text { R-squared }\end{array}$ & 0.009 & 0.021 & 0.021 & 0.025 & 0.052 & 0.053 & 0.059 \\
\hline
\end{tabular}

Table 2: Nightlight Inequality varies at the state level. Average district level nightlight, population density, latitude, longitude, BCG vaccination (in 2017), total vaccination (in 2017) and colonial malaria vary at the district level. Covid19 daily tested varies by state-day. Standard errors in parentheses: $* * * \mathrm{p}<0.01, * * \mathrm{p}<0.05, * \mathrm{p}<0.1$ 


\begin{tabular}{|c|c|c|c|c|c|c|c|c|}
\hline \multicolumn{9}{|c|}{ Dependent Variable: Total Confirmed Covid19 per million population } \\
\hline & (1) & (2) & (3) & (4) & (5) & (6) & (7) & (8) \\
\hline Nightlight & $1.310 * * *$ & $0.690 * * *$ & $0.645^{* * *}$ & $0.604 * * *$ & $0.436 * * *$ & $0.618^{* * *}$ & $0.584 * * *$ & $0.476 * * *$ \\
\hline & $(0.138)$ & $(0.138)$ & (0.138) & (0.138) & $(0.137)$ & $(0.142)$ & $(0.142)$ & (0.139) \\
\hline Days since & & $-0.010 * * *$ & $-0.010 * * *$ & $-0.010 * * *$ & & $-0.011 * * *$ & $-0.011 * * *$ & $-0.008 * * *$ \\
\hline 111.2020 & & $(0.000)$ & $(0.000)$ & $(0.000)$ & $(0.000)$ & $(0.000)$ & $(0.000)$ & $(0.001)$ \\
\hline Nightlight & & $0.054 * * *$ & $0.071 * * *$ & $0.072 * * *$ & $0.072 * * *$ & $0.071 * * *$ & $0.071 * * *$ & $0.072 * * *$ \\
\hline & & $(0.001)$ & $(0.002)$ & $(0.002)$ & $(0.002)$ & $(0.002)$ & $(0.002)$ & $(0.002)$ \\
\hline Daily tested & & $0.032 * * *$ & $0.032 * * *$ & $0.031 * * *$ & $0.031 * * *$ & $0.032 * * *$ & $0.032 * * *$ & $0.050 * * *$ \\
\hline & & $(0.001)$ & $(0.001)$ & $(0.001)$ & $(0.001)$ & $(0.001)$ & $(0.001)$ & $(0.001)$ \\
\hline Population & & & & & - & & & \\
\hline density & & & $\begin{array}{c}-0.092 * * * \\
(0.006)\end{array}$ & $\begin{array}{c}-0.096 * * * \\
(0.007)\end{array}$ & $\begin{array}{c}0.096 * * * \\
(0.006)\end{array}$ & $\begin{array}{c}-0.094^{* * *} \\
(0.006)\end{array}$ & $\begin{array}{c}-0.096 * * * \\
(0.006)\end{array}$ & $\begin{array}{c}-0.097 * * * \\
(0.006)\end{array}$ \\
\hline Temperature & & & & 0.000 & $0.014 * * *$ & $-0.010 * *$ & $-0.011^{* *}$ & $-0.094 * * *$ \\
\hline & & & & $(0.005)$ & $(0.005)$ & $(0.005)$ & (0.005) & $(0.006)$ \\
\hline Rainfall & & & & $\begin{array}{c}0.026 * * * \\
(0.001)\end{array}$ & $\begin{array}{c}0.026 * * * \\
(0.001)\end{array}$ & $\begin{array}{c}0.024^{* * *} \\
(0.001)\end{array}$ & $\begin{array}{c}0.024 * * * \\
(0.001)\end{array}$ & $\begin{array}{c}0.020 * * * \\
(0.001)\end{array}$ \\
\hline $\mathrm{BCG}$ & & & & & 0.004 & $0.006^{* *}$ & $0.007^{* *}$ & $0.007^{* *}$ \\
\hline & & & & & $(0.003)$ & $(0.003)$ & $(0.003)$ & $(0.003)$ \\
\hline $\begin{array}{l}\text { Total } \\
\text { vaccination }\end{array}$ & & & & & $0.014 * * *$ & $0.011^{* * *}$ & $0.009 * * *$ & $0.009 * * *$ \\
\hline & & & & & $(0.002)$ & $(0.002)$ & $(0.002)$ & $(0.002)$ \\
\hline $\begin{array}{l}\text { Colonial } \\
\text { malaria }\end{array}$ & & & & & & $-0.152^{* * *}$ & $-0.137^{* * *}$ & $-0.142 * * *$ \\
\hline & & & & & & $(0.017)$ & (0.018) & (0.017) \\
\hline Latitude & & & & & & & $\begin{array}{c}-0.058^{* * *} \\
(0.015)\end{array}$ & $\begin{array}{c}-0.071 * * * \\
(0.015)\end{array}$ \\
\hline Longitude & & & & & & & $\begin{array}{c}-0.058^{* * *} \\
(0.012)\end{array}$ & $\begin{array}{c}-0.053 * * * \\
(0.012)\end{array}$ \\
\hline Constant & $\begin{array}{c}2.286 * * * \\
(0.121)\end{array}$ & $\begin{array}{c}3.832 * * * \\
(0.133)\end{array}$ & $\begin{array}{c}3.863 * * * \\
(0.132)\end{array}$ & $\begin{array}{c}3.617 * * * \\
(0.274)\end{array}$ & $\begin{array}{c}3.346 * * * \\
(0.349)\end{array}$ & $\begin{array}{c}3.611^{* * *} \\
(0.355)\end{array}$ & $\begin{array}{c}9.487^{* * *} \\
(1.037)\end{array}$ & $\begin{array}{c}13.799 * * * \\
(1.024)\end{array}$ \\
\hline State FE & Yes & Yes & Yes & Yes & Yes & Yes & Yes & Yes \\
\hline State Trend & No & No & No & No & No & No & No & Yes \\
\hline Observations & 148,737 & 147,875 & 147,875 & 147,473 & 145,640 & 139,309 & 139,309 & 139,309 \\
\hline $\begin{array}{l}\text { Adjusted } \\
\text { R-squared }\end{array}$ & 0.086 & 0.114 & 0.115 & 0.115 & 0.116 & 0.118 & 0.119 & 0.157 \\
\hline
\end{tabular}

Table 3: Baseline with neighbourhood nightlight-inequality and state fixed effect. Nightlight Inequality, average district level nightlight, population density, latitude, longitude, BCG vaccination (in 2017), total vaccination (in 2017) and colonial malaria vary at the district level. Covid19 daily tested varies by state-day. Standard errors in parentheses: $* * * \mathrm{p}<0.01, * * \mathrm{p}<0.05, * \mathrm{p}<0.1$ 


\begin{tabular}{|c|c|c|c|c|}
\hline & Phase & Dates & Number of days & Confirmed per million \\
\hline 1 & Pre-Lockdown & 1 Jan, 2020-24 Mar, 2020 & 84 & 0.41 \\
\hline 2 & Lockdown 1 & 25 Mar, 2020 - 14 April, 2020 & 21 & 7.93 \\
\hline 3 & Lockdown 2 & 15 Apr, 2020 - 3 May, 2020 & 19 & 22.86 \\
\hline 4 & Lockdown 3 & 4 May, 2020 -- 17 May, 2020 & 14 & 38.38 \\
\hline 5 & Lockdown 4 & 18 May, 2020 - 31 May, 2020 & 14 & 64.01 \\
\hline 6 & Unlock 1 & 1 June, 2020 - 30 June, 2020 & 30 & 279.00 \\
\hline 7 & Unlock 2 & 1 July, 2020 - 31 July, 2020 & 31 & 784.46 \\
\hline 8 & Unlock 3 & 1 Aug, 2020 - 31 Aug, 2020 & 31 & 1407.29 \\
\hline 9 & Unlock 4 & 1 Sept, $2020-30$ Sept, 2020 & 30 & 1974.05 \\
\hline 10 & Unlock 5 & 1 Oct, $2020-31$ Oct, 2020 & 31 & 1412.30 \\
\hline 11 & Unlock 6 & 1 Nov, 2020 - 30 Nov, 2020 & 30 & 950.53 \\
\hline 12 & Unlock 7 & 1 Dec, $2020-31$ Dec, 2020 & 31 & 605.82 \\
\hline 13 & Unlock 8 & 1 Jan, $2021-31$ Jan, 2021 & 31 & 347.07 \\
\hline
\end{tabular}

Table 4: Phases of India-wide Lockdown and subsequent Unlock as stipulated by the Government of India. Information gathered from various official notifications by the Ministry of Home Affairs, GOI, and media reports. 


\begin{tabular}{|c|c|c|c|c|c|c|}
\hline \multicolumn{7}{|c|}{ Dependent Variable: Total Confirmed Covid19 per million population } \\
\hline & $(1)$ & $(2)$ & (3) & (4) & $(5)$ & $(6)$ \\
\hline & \multicolumn{2}{|c|}{ Lockdown } & \multicolumn{4}{|c|}{ Unlock } \\
\hline & $\begin{array}{c}\text { 4-17 May } \\
2020\end{array}$ & $\begin{array}{c}\text { 18-31 May } \\
2020\end{array}$ & $\begin{array}{c}\text { September } \\
2020\end{array}$ & $\begin{array}{c}\text { October } \\
2020\end{array}$ & $\begin{array}{c}\text { November } \\
2020\end{array}$ & $\begin{array}{c}\text { December } \\
2020\end{array}$ \\
\hline \multirow{2}{*}{$\begin{array}{l}\text { Nightlight } \\
\text { Inequality }\end{array}$} & 3.177 & $-7.603 * *$ & $16.04 * * *$ & $24.86 * * *$ & $22.83 * * *$ & $17.68^{* * *}$ \\
\hline & $(2.834)$ & (3.404) & (3.217) & $(2.420)$ & (3.652) & $(1.694)$ \\
\hline \multirow{2}{*}{$\begin{array}{l}\text { Days since Jan } 1 . \\
2020\end{array}$} & 0.018 & 0.155 & 0.02 & 0.03 & $-0.48^{* *}$ & $-0.85 * * *$ \\
\hline & $(0.452)$ & $(0.503)$ & (0.215) & (0.156) & (0.239) & $(0.110)$ \\
\hline \multirow[t]{2}{*}{ Nightlight } & -0.006 & $-0.135^{* * *}$ & $1.45^{* * *}$ & $1.33^{* * *}$ & $1.31 * * *$ & $0.71^{* * *}$ \\
\hline & $(0.031)$ & $(0.040)$ & (0.039) & (0.029) & $(0.043)$ & (0.019) \\
\hline \multirow[t]{2}{*}{ Daily tested } & 0.01 & 0.02 & $0.36^{* * *}$ & $0.36^{* * *}$ & $0.11^{* * *}$ & $0.20^{* * *}$ \\
\hline & (0.189) & $(0.230)$ & $(0.035)$ & $(0.033)$ & $(0.033)$ & $(0.025)$ \\
\hline \multirow[t]{2}{*}{ Population density } & $0.73 * * *$ & $1.50^{* * *}$ & $-2.78 * * *$ & $-1.76 * * *$ & $-2.08 * * *$ & $-1.10 * * *$ \\
\hline & (0.114) & $(0.152)$ & (0.145) & (0.109) & (0.169) & $(0.074)$ \\
\hline \multirow[t]{2}{*}{ Temperature } & $-0.750 * * *$ & -0.074 & $-0.82^{* * *}$ & $-1.08 * * *$ & $-2.18 * * *$ & $-0.40 * * *$ \\
\hline & $(0.165)$ & $(0.184)$ & $(0.238)$ & $(0.176)$ & $(0.323)$ & $(0.102)$ \\
\hline \multirow[t]{2}{*}{ Rainfall } & -0.190 & -0.009 & 0.00 & 0.01 & -0.06 & -0.03 \\
\hline & $(0.122)$ & $(0.101)$ & $(0.024)$ & $(0.034)$ & $(0.074)$ & $(0.051)$ \\
\hline \multirow[t]{2}{*}{ BCG vaccination } & $0.221 * * *$ & 0.069 & 0.08 & 0.00 & $0.17 * *$ & 0.03 \\
\hline & $(0.060)$ & $(0.076)$ & $(0.072)$ & $(0.054)$ & $(0.081)$ & $(0.038)$ \\
\hline \multirow[t]{2}{*}{ Total vaccination } & $-0.123 * * *$ & -0.034 & $0.47^{* * *}$ & $0.32^{* * *}$ & $0.10^{* *}$ & $0.22^{* * *}$ \\
\hline & $(0.038)$ & $(0.046)$ & $(0.043)$ & $(0.033)$ & (0.049) & $(0.022)$ \\
\hline \multirow[t]{2}{*}{ Colonial malaria } & $-2.345 * * *$ & $-1.813^{* * *}$ & $2.82^{* * *}$ & $-2.49 * * *$ & $-7.57 * * *$ & $-1.70 * * *$ \\
\hline & $(0.349)$ & $(0.434)$ & $(0.401)$ & $(0.301)$ & $(0.447)$ & $(0.203)$ \\
\hline \multirow[t]{2}{*}{ Latitude } & $0.860 * * *$ & -0.405 & -0.46 & $-0.78 * * *$ & 0.02 & $0.54^{* * *}$ \\
\hline & $(0.290)$ & $(0.359)$ & (0.339) & $(0.255)$ & $(0.404)$ & (0.189) \\
\hline \multirow[t]{2}{*}{ Longitude } & $-0.609 * *$ & $-1.059 * * *$ & $-1.74 * * *$ & 0.32 & $1.82^{* * *}$ & $0.29 * *$ \\
\hline & $(0.237)$ & $(0.293)$ & $(0.273)$ & $(0.206)$ & $(0.310)$ & (0.141) \\
\hline \multirow[t]{2}{*}{ Constant } & 38.124 & $98.519 * * *$ & $215.92^{* * *}$ & $267.60 * * *$ & 41.19 & $121.31 * * *$ \\
\hline & $(23.447)$ & $(28.406)$ & $(28.642)$ & $(23.068)$ & (37.819) & (19.637) \\
\hline State FE & Yes & Yes & Yes & Yes & Yes & Yes \\
\hline State Trend & Yes & Yes & Yes & Yes & Yes & Yes \\
\hline Observations & 6,133 & 6,948 & 15,507 & 15,926 & 15,154 & 14,908 \\
\hline Adjusted R-squared & 0.154 & 0.117 & 0.490 & 0.568 & 0.330 & 0.571 \\
\hline
\end{tabular}

Table 5: Heterogeneity with neighbourhood inequality for lockdown and unlock phases. Nightlight Inequality, average district level nightlight, population density normalized by 1000 , latitude, longitude, BCG vaccination (in 2017), total vaccination (in 2017) and colonial malaria vary at the district level. Covid19 daily tested, normalized by 1000 , varies by state-day. Standard errors in parentheses: $* * * \mathrm{p}<0.01,{ }^{* *} \mathrm{p}<0.05,{ }^{*} \mathrm{p}<0.1$ 


\begin{tabular}{|c|c|c|c|c|c|c|c|c|}
\hline \multicolumn{9}{|c|}{ Dependent Variable: Number of people moving across districts in '0000 } \\
\hline & (1) & (2) & (3) & (4) & $(5)$ & $(6)$ & $(7)$ & $(8)$ \\
\hline Nightlight Inequality & $\begin{array}{c}40.598 * * * \\
(0.659)\end{array}$ & $\begin{array}{c}26.038^{* * *} \\
(0.535)\end{array}$ & $\begin{array}{c}26.193 * * * \\
(0.534)\end{array}$ & $\begin{array}{c}24.412^{* * *} \\
(0.512)\end{array}$ & $\begin{array}{c}23.409 * * * \\
(0.515)\end{array}$ & $\begin{array}{c}25.676 * * * \\
(0.558)\end{array}$ & $\begin{array}{c}25.769 * * * \\
(0.557)\end{array}$ & $\begin{array}{c}25.789 * * * \\
(0.557)\end{array}$ \\
\hline Days since Jan 1.2020 & & $\begin{array}{c}-0.017^{* * *} \\
(0.001)\end{array}$ & $\begin{array}{c}-0.017^{* * *} \\
(0.001)\end{array}$ & $\begin{array}{c}-0.016 * * * \\
(0.002)\end{array}$ & $\begin{array}{c}-0.015^{* * *} \\
(0.002)\end{array}$ & $\begin{array}{c}-0.015^{* * *} \\
(0.002)\end{array}$ & $\begin{array}{c}-0.014 * * * \\
(0.002)\end{array}$ & $\begin{array}{c}-0.029 * * * \\
(0.005)\end{array}$ \\
\hline Nightlight & & $\begin{array}{c}1.240 * * * \\
(0.005)\end{array}$ & $\begin{array}{c}1.168^{* * *} \\
(0.007)\end{array}$ & $\begin{array}{c}1.368^{* * *} \\
(0.007)\end{array}$ & $\begin{array}{c}1.359 * * * \\
(0.007)\end{array}$ & $\begin{array}{c}1.355^{* * *} \\
(0.007)\end{array}$ & $\begin{array}{c}1.363^{* * *} \\
(0.007)\end{array}$ & $\begin{array}{c}1.363^{* * *} \\
(0.007)\end{array}$ \\
\hline Daily tested & & $\begin{array}{c}-0.008 * * * \\
(0.003)\end{array}$ & $\begin{array}{c}-0.008 * * * \\
(0.003)\end{array}$ & $\begin{array}{c}-0.008 * * * \\
(0.003)\end{array}$ & $\begin{array}{c}-0.008 * * * \\
(0.003)\end{array}$ & $\begin{array}{c}-0.008^{* * *} \\
(0.003)\end{array}$ & $\begin{array}{c}-0.008 * * * \\
(0.003)\end{array}$ & $\begin{array}{c}-0.005 \\
(0.003)\end{array}$ \\
\hline Population density & & & $\begin{array}{c}0.382 * * * \\
(0.026)\end{array}$ & $\begin{array}{c}0.803^{* * *} \\
(0.025)\end{array}$ & $\begin{array}{c}0.806 * * * \\
(0.025)\end{array}$ & $\begin{array}{c}0.810^{* * *} \\
(0.025)\end{array}$ & $\begin{array}{c}0.746^{* * *} \\
(0.025)\end{array}$ & $\begin{array}{c}0.746^{* * *} \\
(0.025)\end{array}$ \\
\hline Temperature & & & & $\begin{array}{c}0.013 \\
(0.020)\end{array}$ & $\begin{array}{l}0.036^{*} \\
(0.020)\end{array}$ & $\begin{array}{c}0.045 * * \\
(0.021)\end{array}$ & $\begin{array}{c}0.066^{* * *} \\
(0.021)\end{array}$ & $\begin{array}{c}0.096 * * * \\
(0.024)\end{array}$ \\
\hline Rainfall & & & & $\begin{array}{c}0.002 \\
(0.005)\end{array}$ & $\begin{array}{c}-0.001 \\
(0.005)\end{array}$ & $\begin{array}{l}-0.000 \\
(0.006)\end{array}$ & $\begin{array}{c}0.001 \\
(0.006)\end{array}$ & $\begin{array}{c}0.002 \\
(0.006)\end{array}$ \\
\hline BCG vaccination & & & & & $\begin{array}{c}0.116 * * * \\
(0.012)\end{array}$ & $\begin{array}{c}0.106^{* * *} \\
(0.013)\end{array}$ & $\begin{array}{c}0.111^{* * *} \\
(0.013)\end{array}$ & $\begin{array}{c}0.110^{* * *} \\
(0.013)\end{array}$ \\
\hline Total vaccination & & & & & $\begin{array}{c}0.127^{* * *} \\
(0.008)\end{array}$ & $\begin{array}{c}0.138^{* * *} \\
(0.008)\end{array}$ & $\begin{array}{c}0.140 * * * \\
(0.008)\end{array}$ & $\begin{array}{c}0.141^{* * *} \\
(0.008)\end{array}$ \\
\hline Colonial malaria & & & & & & $\begin{array}{l}-0.109 \\
(0.077)\end{array}$ & $\begin{array}{c}0.400 * * * \\
(0.079)\end{array}$ & $\begin{array}{c}0.408^{* * *} \\
(0.079)\end{array}$ \\
\hline Latitude & & & & & & & $\begin{array}{c}0.391 * * * \\
(0.061)\end{array}$ & $\begin{array}{c}0.397^{* * *} \\
(0.061)\end{array}$ \\
\hline Longitude & & & & & & & $\begin{array}{c}-1.369 * * * \\
(0.048)\end{array}$ & $\begin{array}{c}-1.371 * * * \\
(0.048)\end{array}$ \\
\hline Constant & $\begin{array}{c}- \\
11.981^{* * *} \\
(0.571)\end{array}$ & $\begin{array}{c}-0.624 \\
(0.517)\end{array}$ & $\begin{array}{c}-0.719 \\
(0.517)\end{array}$ & $\begin{array}{c}-0.730 \\
(1.067)\end{array}$ & $\begin{array}{c}- \\
17.913^{* * *} \\
(1.358)\end{array}$ & $\begin{array}{c}- \\
18.797^{* * *} \\
(1.452)\end{array}$ & $\begin{array}{c}76.700 * * * \\
(4.168)\end{array}$ & $\begin{array}{c}75.356 * * * \\
(4.211)\end{array}$ \\
\hline State FE & Yes & Yes & Yes & Yes & Yes & Yes & Yes & Yes \\
\hline State Trend & No & No & No & No & No & No & No & Yes \\
\hline Observations & 142,933 & 142,147 & 142,147 & 141,756 & 140,392 & 133,735 & 133,735 & 133,735 \\
\hline Adjusted R-squared & 0.134 & 0.437 & 0.438 & 0.484 & 0.488 & 0.484 & 0.487 & 0.487 \\
\hline
\end{tabular}

Table 6: Regression with Facebook-migration across districts as the dependent variable. Nightlight Inequality, average district level nightlight, population density normalized by 1000, latitude, longitude, BCG vaccination (in 2017), total vaccination (in 2017) and colonial malaria vary at the district level. Covid19 daily tested, normalized by 1000 , varies by state-day. Standard errors in parentheses: $* * * \mathrm{p}<0.01, * * \mathrm{p}<0.05, * \mathrm{p}<0.1$ 


\begin{tabular}{|c|c|c|c|c|c|c|}
\hline \multicolumn{7}{|c|}{ Dependent Variable: Total Confirmed Covid19 per million population } \\
\hline & Panel A & & & Panel B & & \\
\hline & $(1)$ & $(2)$ & $(3)$ & $(4)$ & $(5)$ & $(6)$ \\
\hline & Baseline & FB Mobility & \multicolumn{4}{|c|}{ Unemployment } \\
\hline Nightlight Inequality (NI) & $\begin{array}{c}0.593 * * * \\
(0.127)\end{array}$ & $\begin{array}{c}0.106 \\
(0.128)\end{array}$ & $\begin{array}{c}4.457 * * * \\
(0.284)\end{array}$ & $\begin{array}{c}14.790 * * * \\
(0.844)\end{array}$ & & \\
\hline FB Mobility & & $\begin{array}{c}0.019 * * * \\
(0.001)\end{array}$ & & & & \\
\hline NI* Unemployment & & & $\begin{array}{c}-0.070 * * * \\
(0.020)\end{array}$ & $\begin{array}{c}-0.318 * * * \\
(0.027)\end{array}$ & $\begin{array}{c}-0.178 * * * \\
(0.024)\end{array}$ & $\begin{array}{c}-0.293 * * * \\
(0.033)\end{array}$ \\
\hline Unemployment & & & $\begin{array}{l}-0.098^{*} \\
(0.058)\end{array}$ & $\begin{array}{c}0.267 * * * \\
(0.077)\end{array}$ & $\begin{array}{c}-0.256^{* * *} \\
(0.072)\end{array}$ & $\begin{array}{c}-0.367 * * * \\
(0.094)\end{array}$ \\
\hline Constant & $\begin{array}{c}12.894 * * * \\
(0.962)\end{array}$ & $\begin{array}{c}11.482 * * * \\
(0.960)\end{array}$ & $\begin{array}{c}93.860 * * * \\
(4.835)\end{array}$ & $\begin{array}{c}39.418 * * * \\
(8.031)\end{array}$ & $\begin{array}{c}118.980 * * * \\
(10.295)\end{array}$ & $\begin{array}{c}157.303 * * * \\
(10.132)\end{array}$ \\
\hline Control Variables & Yes & Yes & Yes & Yes & Yes & Yes \\
\hline State FE & Yes & Yes & No & No & Yes & Yes \\
\hline State Trend & Yes & Yes & No & Yes & No & Yes \\
\hline Observations & 130,875 & 130,875 & 139,309 & 139,309 & 139,309 & 139,309 \\
\hline Adjusted R-squared & 0.186 & 0.191 & 0.060 & 0.141 & 0.123 & 0.163 \\
\hline
\end{tabular}

Table 7: This Table explores mobility as the underlying mechanism. Columns 1 corresponds to Column 8 of Table 3. Columns 2 introduces an additional control for inter-district mobility. In Columns 3-6 Nightlight Inequality varies at the state level and Unemployment varies by state-month. Control Variables are as same as in Table 3. Standard errors in parentheses: $* * * \mathrm{p}<0.01$, $* * \mathrm{p}<0.05, * \mathrm{p}<0.1$ 
Appendix

\begin{tabular}{|c|c|c|c|}
\hline State Name & Variable Name & Availability & $\begin{array}{l}\text { Date Range for } \\
\text { Variable Availability }\end{array}$ \\
\hline \multirow[t]{3}{*}{$\begin{array}{l}\text { Andaman and Nicobar } \\
\text { Islands }\end{array}$} & Total confirmed & Partial districts, no missing date & $\begin{array}{l}4 \text { days in Mar'20 | } 10 \text { days } \\
\text { in Apr'20 }\end{array}$ \\
\hline & Daily confirmed & Partial districts, no missing date & $\begin{array}{l}4 \text { days in Mar'20 | } 10 \text { days } \\
\text { in Apr'20 }\end{array}$ \\
\hline & $\begin{array}{ll}\text { Covid } & \text { Tests } \\
\text { (Daily) } & \\
\end{array}$ & $\begin{array}{l}\text { Partial districts, missing dates } \\
\text { interpolated }\end{array}$ & $\begin{array}{l}3 \text { days in Mar'20 | } 10 \text { days } \\
\text { in Apr'20 }\end{array}$ \\
\hline \multirow[t]{3}{*}{ Andhra Pradesh } & Total confirmed & All districts, but missing dates & $\begin{array}{l}13 \text { days in Mar'20 | 1st } \\
\text { Apr'20 - 31st Jan'21 }\end{array}$ \\
\hline & Daily confirmed & All districts, but missing dates & $\begin{array}{l}13 \text { days in Mar'20 | 1st } \\
\text { Apr'20 - 31st Jan'21 }\end{array}$ \\
\hline & $\begin{array}{ll}\text { Covid } & \text { Tests } \\
\text { (Daily) } & \end{array}$ & All districts, but missing dates & $\begin{array}{l}9 \text { days in Mar'20 | 1st } \\
\text { Apr'20 - 31st Jan'21 }\end{array}$ \\
\hline \multirow[t]{3}{*}{ Arunachal Pradesh } & Total confirmed & All districts, but missing dates & $\begin{array}{l}6 \text { days in Apr'20 | 1st } \\
\text { May'20 - 31st Jan'21 }\end{array}$ \\
\hline & Daily confirmed & All districts, but missing dates & $\begin{array}{l}6 \text { days in Apr'20 | 1st } \\
\text { May'20 - 31st Jan'21 }\end{array}$ \\
\hline & $\begin{array}{ll}\text { Covid } & \text { Tests } \\
\text { (Daily) } & \end{array}$ & All districts, but missing dates & $\begin{array}{l}5 \text { days in Apr'20 | 1st } \\
\text { May'20 - 31st Jan'21 }\end{array}$ \\
\hline \multirow[t]{3}{*}{ Assam } & Total confirmed & All districts, but missing dates & $\begin{array}{l}\text { 31st Mar'20 - 19th } \\
\text { Aug'20 }\end{array}$ \\
\hline & Daily confirmed & All districts, but missing dates & $\begin{array}{l}\text { 31st Mar'20 - 19th } \\
\text { Aug'20 }\end{array}$ \\
\hline & $\begin{array}{ll}\text { Covid } & \text { Tests } \\
\text { (Daily) } & \end{array}$ & All districts, but missing dates & 3rd Apr'20 - 19th Aug'20 \\
\hline \multirow[t]{3}{*}{ Bihar } & Total confirmed & All districts, but missing dates & 22nd Mar'20 - 31st Jan'21 \\
\hline & Daily confirmed & All districts, but missing dates & 22nd Mar'20 - 31st Jan'21 \\
\hline & $\begin{array}{ll}\text { Covid } & \text { Tests } \\
\text { (Daily) } & \\
\end{array}$ & All districts, but missing dates & 23rd Mar'20 - 31st Jan'21 \\
\hline \multirow[t]{3}{*}{ Chandigarh } & Total confirmed & All districts, no missing dates & 19th Mar'20 - 31st Jan'21 \\
\hline & Daily confirmed & All districts, no missing dates & 20th Mar'20 - 31st Jan'21 \\
\hline & $\begin{array}{ll}\text { Covid } & \text { Tests } \\
\text { (Daily) } & \\
\end{array}$ & All districts, no missing dates & 20th Mar'20 - 31st Jan'21 \\
\hline \multirow[t]{3}{*}{ Chhattisgarh } & Total confirmed & All districts, but missing dates & 19th Mar'20 - 31st Jan'21 \\
\hline & Daily confirmed & All districts, but missing dates & 19th Mar'20 - 31st Jan'21 \\
\hline & $\begin{array}{ll}\begin{array}{l}\text { Covid } \\
\text { (Daily) }\end{array} & \text { Tests } \\
\end{array}$ & All districts, but missing dates & 25th Mar'20 - 31st Jan'21 \\
\hline \multirow{3}{*}{$\begin{array}{l}\text { Daman diu and dadra } \\
\text { nagar haveli }\end{array}$} & Total confirmed & All districts, but missing dates & 5th May'20 - 31st Jan'21 \\
\hline & Daily confirmed & All districts, but missing dates & 5th May'20 - 31st Jan'21 \\
\hline & $\begin{array}{ll}\begin{array}{l}\text { Covid } \\
\text { (Daily) }\end{array} & \text { Tests } \\
\end{array}$ & All districts, but missing dates & 6th May'20 - 31st Jan'21 \\
\hline \multirow[t]{3}{*}{ Delhi } & Total confirmed & State level, no missing dates & 2nd Mar'20 - 31st Jan'21 \\
\hline & Daily confirmed & State level, no missing dates & 3rd Mar'20 - 31st Jan'21 \\
\hline & $\begin{array}{l}\text { Covid } \\
\text { (Daily) }\end{array}$ & State level, no missing dates & 3rd Mar'20 - 31st Jan'21 \\
\hline \multirow[t]{2}{*}{ Goa } & Total confirmed & All districts, no missing dates & $\begin{array}{l}\text { 25th Mar'20|4th Apr'20 } \\
\text { 26th Apr'20 - 19th } \\
\text { Aug'20 }\end{array}$ \\
\hline & Daily confirmed & All districts, no missing dates & $\begin{array}{l}\text { 25th Mar'20|4th Apr'20 } \\
\text { 26th Apr'20 - 19th } \\
\text { Aug'20 }\end{array}$ \\
\hline
\end{tabular}




\begin{tabular}{|c|c|c|c|}
\hline & $\begin{array}{ll}\text { Covid } & \text { Tests } \\
\text { (Daily) } & \end{array}$ & All districts, but missing dates & $\begin{array}{l}\text { 25th Mar'20|4th Apr'20 } \\
\text { 26th Apr'20 - 19th } \\
\text { Aug'20 }\end{array}$ \\
\hline \multirow[t]{3}{*}{ Gujarat } & Total confirmed & All districts, but missing dates & 19th Mar'20 - 31st Jan'21 \\
\hline & Daily confirmed & All districts, but missing dates & 19th Mar'20 - 31st Jan'21 \\
\hline & $\begin{array}{ll}\begin{array}{l}\text { Covid } \\
\text { (Daily) }\end{array} & \text { Tests } \\
\end{array}$ & All districts, but missing dates & 21st Mar'20 - 31st Jan'21 \\
\hline \multirow[t]{3}{*}{ Haryana } & Total confirmed & All districts, but missing dates & 17th Mar'20 - 31st Jan'21 \\
\hline & Daily confirmed & All districts, but missing dates & 17th Mar'20 - 31st Jan'21 \\
\hline & $\begin{array}{ll}\begin{array}{l}\text { Covid } \\
\text { (Daily) }\end{array} & \text { Tests } \\
\end{array}$ & All districts, but missing dates & 18th Mar'20 - 31st Jan'21 \\
\hline \multirow[t]{3}{*}{ Himachal Pradesh } & Total confirmed & All districts, but missing dates & 20th Mar'20 - 31st Jan'21 \\
\hline & Daily confirmed & All districts, but missing dates & 23rd Mar'20 - 31st Jan'21 \\
\hline & $\begin{array}{ll}\begin{array}{l}\text { Covid } \\
\text { (Daily) }\end{array} & \text { Tests } \\
\end{array}$ & All districts, but missing dates & 23rd Mar'20 - 31st Jan'21 \\
\hline \multirow[t]{3}{*}{ Jammu and Kashmir } & Total confirmed & All districts, but missing dates & 9th Mar'20 - 31st Jan'21 \\
\hline & Daily confirmed & All districts, but missing dates & 9th Mar'20 - 31st Jan'21 \\
\hline & $\begin{array}{ll}\begin{array}{l}\text { Covid } \\
\text { (Daily) }\end{array} & \text { Tests } \\
\end{array}$ & All districts, but missing dates & 13th Mar'20 - 31st Jan'21 \\
\hline \multirow[t]{3}{*}{ Jharkhand } & Total confirmed & All districts, but missing dates & 31st Mar'20 - 31st Jan'21 \\
\hline & Daily confirmed & All districts, but missing dates & 6th Apr'20 - 31st Jan'21 \\
\hline & $\begin{array}{ll}\begin{array}{l}\text { Covid } \\
\text { (Daily) }\end{array} & \text { Tests } \\
\end{array}$ & All districts, but missing dates & 6th Apr'20 - 31st Jan'21 \\
\hline \multirow[t]{3}{*}{ Karnataka } & Total confirmed & Partial districts, no missing date & 9th Mar'20 - 31st Jan'21 \\
\hline & Daily confirmed & $\begin{array}{l}\text { Partial districts, missing dates } \\
\text { interpolated }\end{array}$ & 10th Mar'20 - 31st Jan'21 \\
\hline & $\begin{array}{ll}\begin{array}{l}\text { Covid } \\
\text { (Daily) }\end{array} & \text { Tests } \\
\end{array}$ & $\begin{array}{l}\text { Partial districts, missing dates } \\
\text { interpolated }\end{array}$ & 10th Mar'20 - 31st Jan'21 \\
\hline \multirow[t]{3}{*}{ Kerala } & Total confirmed & All districts, but missing dates & $\begin{array}{l}\text { 30th Jan'20 | 2nd - 3rd } \\
\text { Feb'20|8th Mar'20 - 31st } \\
\text { Jan'21 }\end{array}$ \\
\hline & Daily confirmed & All districts, but missing dates & $\begin{array}{l}\text { 30th Jan'20 | 2nd - 3rd } \\
\text { Feb'20|8th Mar'20 - 31st } \\
\text { Jan'21 }\end{array}$ \\
\hline & $\begin{array}{ll}\begin{array}{l}\text { Covid } \\
\text { (Daily) }\end{array} & \text { Tests } \\
\end{array}$ & All districts, but missing dates & 10th Mar'20 - 31st Jan'21 \\
\hline \multirow[t]{3}{*}{ Ladakh } & Total confirmed & All districts, but missing dates & 7th Mar'20 - 31st Jan'21 \\
\hline & Daily confirmed & All districts, but missing dates & 11th Mar'20 - 31st Jan'21 \\
\hline & $\begin{array}{l}\text { Covid } \\
\text { (Daily) }\end{array}$ & All districts, but missing dates & 11th Mar'20 - 31st Jan'21 \\
\hline \multirow[t]{3}{*}{ Lakshadweep } & Total confirmed & All districts, but missing dates & 18th - 31st Jan'21 \\
\hline & Daily confirmed & All districts, but missing dates & 19th - 31st Jan'21 \\
\hline & $\begin{array}{ll}\begin{array}{l}\text { Covid } \\
\text { (Daily) }\end{array} & \text { Tests } \\
\end{array}$ & All districts, but missing dates & 19th - 31st Jan'21 \\
\hline \multirow[t]{3}{*}{ Madhya Pradesh } & Total confirmed & All districts, but missing dates & 20th Mar'20 - 31st Jan'21 \\
\hline & Daily confirmed & All districts, but missing dates & 22nd Mar'20 - 31st Jan'21 \\
\hline & $\begin{array}{l}\text { Covid } \\
\text { (Daily) }\end{array}$ & All districts, but missing dates & 22nd Mar'20 - 31st Jan'21 \\
\hline \multirow[t]{3}{*}{ Maharashtra } & Total confirmed & All districts, but missing dates & 9th Mar'20 - 31st Jan'21 \\
\hline & Daily confirmed & All districts, but missing dates & 9th Mar'20 - 31st Jan'21 \\
\hline & $\begin{array}{l}\text { Covid } \\
\text { (Daily) }\end{array}$ & All districts, but missing dates & 10th Mar'20 - 31st Jan'21 \\
\hline
\end{tabular}




\begin{tabular}{|c|c|c|c|}
\hline \multirow[t]{2}{*}{ Manipur } & \multirow{2}{*}{$\begin{array}{l}\text { Total confirmed } \\
\text { Daily confirmed }\end{array}$} & \multirow{2}{*}{$\begin{array}{l}\text { All districts, but missing dates } \\
\text { All districts, but missing dates }\end{array}$} & \multirow{2}{*}{$\begin{array}{l}\text { 24th Mar'20|2nd Apr'20 } \\
\mid \text { 26th Apr'20 - 19th } \\
\text { Aug'20 } \\
\text { 24th Mar'20|2nd Apr'20 } \\
\text { | 26th Apr'20 - 19th } \\
\text { Aug'20 }\end{array}$} \\
\hline & & & \\
\hline & $\begin{array}{ll}\text { Covid } & \text { Tests } \\
\text { (Daily) } & \end{array}$ & All districts, but missing dates & $\begin{array}{l}\text { 26th Apr'20 - 19th } \\
\text { Aug'20 }\end{array}$ \\
\hline \multirow[t]{3}{*}{ Meghalaya } & Total confirmed & All districts, but missing dates & 13th Apr'20 - 31st Jan'21 \\
\hline & Daily confirmed & All districts, but missing dates & 15th Apr'20 - 31st Jan'21 \\
\hline & $\begin{array}{ll}\begin{array}{l}\text { Covid } \\
\text { (Daily) }\end{array} & \text { Tests } \\
\end{array}$ & All districts, but missing dates & 15th Apr'20 - 31st Jan'21 \\
\hline \multirow[t]{3}{*}{ Mizoram } & Total confirmed & All districts, but missing dates & $\begin{array}{l}\text { 25th Mar'20|26th Apr'20 } \\
-31 \text { st Jan'21 }\end{array}$ \\
\hline & Daily confirmed & All districts, but missing dates & 26th Apr'20 - 31st Jan'21 \\
\hline & $\begin{array}{ll}\begin{array}{l}\text { Covid } \\
\text { (Daily) }\end{array} & \text { Tests } \\
\end{array}$ & All districts, but missing dates & 26th Apr'20 - 31st Jan'21 \\
\hline \multirow[t]{3}{*}{ Nagaland } & Total confirmed & All districts, but missing dates & 19th May'20 - 31st Jan'21 \\
\hline & Daily confirmed & All districts, but missing dates & 20th May'20 - 31st Jan'21 \\
\hline & $\begin{array}{ll}\begin{array}{l}\text { Covid } \\
\text { (Daily) }\end{array} & \text { Tests } \\
\end{array}$ & All districts, but missing dates & 20th May'20 - 31st Jan'21 \\
\hline \multirow[t]{3}{*}{ Odisha } & Total confirmed & All districts, but missing dates & 16th Mar'20 - 31st Jan'21 \\
\hline & Daily confirmed & All districts, but missing dates & 19th Mar'20 - 31st Jan'21 \\
\hline & $\begin{array}{ll}\begin{array}{l}\text { Covid } \\
\text { (Daily) }\end{array} & \text { Tests } \\
\end{array}$ & All districts, but missing dates & 19th Mar'20 - 31st Jan'21 \\
\hline \multirow[t]{3}{*}{ Puducherry } & Total confirmed & All districts, but missing dates & $\begin{array}{l}\text { 17th Mar'20|1st }-2 \text { nd } \\
\text { Apr'20|10th Apr'20 } \\
25 \text { th Apr'20-31st Jan'21 }\end{array}$ \\
\hline & Daily confirmed & All districts, but missing dates & $\begin{array}{l}\text { 2nd Apr'20 | 10th Apr'20 } \\
\text { 25th Apr'20 - 31st Jan'21 }\end{array}$ \\
\hline & $\begin{array}{ll}\begin{array}{l}\text { Covid } \\
\text { (Daily) }\end{array} & \text { Tests } \\
\end{array}$ & All districts, but missing dates & $\begin{array}{l}\text { 2nd Apr'20 | 10th Apr'20 } \\
\text { 25th Apr'20 - 31st Jan'21 }\end{array}$ \\
\hline \multirow[t]{3}{*}{ Punjab } & Total confirmed & All districts, but missing dates & 9th Mar'20 - 31st Jan'21 \\
\hline & Daily confirmed & All districts, but missing dates & 21st Mar'20 - 31st Jan'21 \\
\hline & $\begin{array}{ll}\text { Covid } & \text { Tests } \\
\text { (Daily) } & \end{array}$ & All districts, but missing dates & 21st Mar'20 - 31st Jan'21 \\
\hline \multirow[t]{3}{*}{ Rajasthan } & Total confirmed & All districts, but missing dates & 10th Mar'20 - 31st Jan'21 \\
\hline & Daily confirmed & All districts, but missing dates & 14th Mar'20 - 31st Jan'21 \\
\hline & $\begin{array}{ll}\begin{array}{l}\text { Covid } \\
\text { (Daily) }\end{array} & \text { Tests } \\
\end{array}$ & All districts, but missing dates & 14th Mar'20 - 31st Jan'21 \\
\hline \multirow[t]{3}{*}{ Sikkim } & Total confirmed & All districts, but missing dates & $\begin{array}{l}\text { 23rd May'20 - 19th } \\
\text { Aug'20 }\end{array}$ \\
\hline & Daily confirmed & All districts, but missing dates & $\begin{array}{l}\text { 23rd May'20 - 19th } \\
\text { Aug'20 }\end{array}$ \\
\hline & $\begin{array}{ll}\begin{array}{l}\text { Covid } \\
\text { (Daily) }\end{array} & \text { Tests } \\
\end{array}$ & All districts, but missing dates & $\begin{array}{l}\text { 24th May'20 - 19th } \\
\text { Aug'20 }\end{array}$ \\
\hline \multirow[t]{3}{*}{ Tamil Nadu } & Total confirmed & Partial districts and missing dates & 7th Mar'20 - 31st Jan'21 \\
\hline & Daily confirmed & Partial districts and missing dates & 19th Mar'20 - 31st Jan'21 \\
\hline & $\begin{array}{ll}\begin{array}{l}\text { Covid } \\
\text { (Daily) }\end{array} & \text { Tests } \\
\end{array}$ & Partial districts and missing dates & 19th Mar'20 - 31st Jan'21 \\
\hline \multirow[t]{2}{*}{ Telangana } & Total confirmed & Partial districts and missing dates & $\begin{array}{l}\text { 2nd Mar'20|14th Mar'20 } \\
\text { - 26th Apr'20 }\end{array}$ \\
\hline & Daily confirmed & Partial districts and missing dates & $\begin{array}{l}\text { 2nd Mar'20|14th Mar'20 } \\
\text { - 26th Apr'20 }\end{array}$ \\
\hline
\end{tabular}




\begin{tabular}{|l|l|l|l|}
\hline & $\begin{array}{l}\text { Covid Tests } \\
\text { (Daily) }\end{array}$ & Partial districts and missing dates & $\begin{array}{l}\text { 14th Mar'20 - 26th } \\
\text { Apr'20 }\end{array}$ \\
\hline Tripura & Total confirmed & All districts, but missing dates & $\begin{array}{l}\text { 6th Apr'20|10th Apr'20 | } \\
\text { 26th Apr'20 - 31st Jan'21 }\end{array}$ \\
\hline & Daily confirmed & All districts, but missing dates & 26th Apr'20 - 31st Jan'21 \\
\hline & $\begin{array}{l}\text { Covid Tests } \\
\text { (Daily) }\end{array}$ & All districts, but missing dates & 26th Apr'20 - 31st Jan'21 \\
\hline Uttar Pradesh & Total confirmed & All districts, but missing dates & $\begin{array}{l}\text { 4th - 5th Mar'20 | 9th } \\
\text { Mar'20 - 31st Jan'21 }\end{array}$ \\
\hline & Daily confirmed & All districts, but missing dates & 9th Mar'20 - 31st Jan'21 \\
\hline & $\begin{array}{l}\text { Covid Tests } \\
\text { (Daily) }\end{array}$ & All districts, but missing dates & 9th Mar'20 - 31st Jan'21 \\
\hline Uttarakhand & Total confirmed & All districts, but missing dates & 15th Mar'20 - 31st Jan'21 \\
\hline & Daily confirmed & All districts, but missing dates & 19th Mar'20 - 31st Jan'21 \\
\hline & $\begin{array}{l}\text { Covid Tests } \\
\text { (Daily) }\end{array}$ & All districts, but missing dates & 19th Mar'20 - 31st Jan'21 \\
\hline West Bengal & Total confirmed & All districts, but missing dates & 17th Mar'20 - 31st Jan'21 \\
\hline & Daily confirmed & All districts, but missing dates & 17th Mar'20 - 31st Jan'21 \\
\hline & $\begin{array}{l}\text { Covid Tests } \\
\text { (Daily) }\end{array}$ & All districts, but missing dates & 20th Mar'20 - 31st Jan'21 \\
\hline
\end{tabular}

Table A1: Data availability

Notes: For each state, this table lists the availability of data, on total confirmed cases, daily confirmed cases and covid tests conducted, across districts and over time. 


\begin{tabular}{|c|c|c|c|c|}
\hline Phase & Dates & $\begin{array}{l}\text { Numb } \\
\text { er of } \\
\text { days }\end{array}$ & Regulations & Source \\
\hline $\begin{array}{l}\text { Pre- } \\
\text { Lockdo } \\
\text { wn }\end{array}$ & $\begin{array}{l}1 \quad \text { Jan, } \\
2020- \\
24 \text { Mar, } \\
2020\end{array}$ & 84 & Business as Usual & \\
\hline $\begin{array}{l}\text { Lockdo } \\
\text { wn } 1\end{array}$ & $\begin{array}{l}25 \text { Mar, } \\
2020- \\
14 \\
\text { April, } \\
2020\end{array}$ & 21 & $\begin{array}{l}\text { All services and factories, except essential, were suspended. Arrests across the } \\
\text { states were made for violating norms of lockdown such as venturing out for no } \\
\text { emergency, opening businesses and also home quarantine violations. } \\
\text { The national rail network has maintained its freight operations during the } \\
\text { lockdown, to transport essential goods. On } 29 \text { March, the Indian Railways } \\
\text { announced that it would start services for special parcel trains to transport } \\
\text { essential goods, in addition to the regular freight service. } \\
\text { As the end of the initial lockdown period came near, many state governments } \\
\text { expressed their decision to extend it till the end of April. Among them were } \\
\text { Odisha, Punjab, Maharashtra, Karnataka with some relaxations, West Bengal } \\
\text { and }\end{array}$ & $\begin{array}{l}\text { https://ww } \\
\text { w.mha.go } \\
\text { v.in/sites/ } \\
\text { default/fil } \\
\text { es/Guideli } \\
\text { nes 0.pdf }\end{array}$ \\
\hline $\begin{array}{l}\text { Lockdo } \\
\text { wn } 2\end{array}$ & $\begin{array}{l}15 \text { Apr, } \\
2020- \\
3 \text { May, } \\
2020\end{array}$ & 19 & $\begin{array}{l}\text { On } 14 \text { April, the nationwide lockdown was extended till } 3 \text { May, with a } \\
\text { conditional relaxation promised after } 20 \text { April for the regions where the spread } \\
\text { had been contained by then. Every police station area were to be evaluated to } \\
\text { see if it had contained the spread. The areas that were able to do so would be } \\
\text { released from the lockdown on } 20 \text { April. If any new cases emerged in those } \\
\text { areas, could } \\
\text { lockdown be } \\
\text { On } 16 \text { April, lockdown areas were classified as "red zone", indicating the } \\
\text { presence of infection hotspots, "orange zone" indicating some infection, and } \\
\text { "green zone" with no infections in the past } 21 \text { days. } \\
\text { The government also announced certain relaxations from } 20 \text { April, allowing } \\
\text { agricultural businesses, including dairy, aquaculture, and plantations, as well as } \\
\text { shops selling farming supplies, to open. Public works programmes were also } \\
\text { allowed to reopen with instructions to maintain social distancing. Cargo } \\
\text { vehicles, including trucks, trains, and planes, would run. Banks and government } \\
\text { centres distributing benefits would open as well with limited timings. } \\
\text { On } 25 \text { April, small retail shops were allowed to open with half the staff. Again, } \\
\text { social distancing norms } \\
\text { On } 29 \text { April, The Ministry of Home Affairs issued guidelines for the states to } \\
\text { allow inter-state movement of the stranded persons. States have been asked to } \\
\text { designate nodal authorities and form protocols to receive and send such persons. }\end{array}$ & 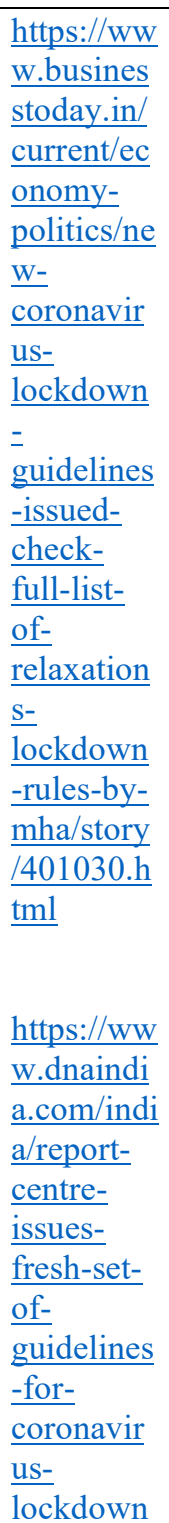 \\
\hline
\end{tabular}




\begin{tabular}{|c|c|c|c|c|}
\hline & & & & 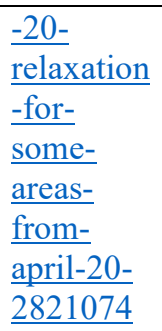 \\
\hline $\begin{array}{l}\text { Lockdo } \\
\text { wn } 3\end{array}$ & $\begin{array}{l}4 \text { May, } \\
2020-- \\
17 \\
\text { May, } \\
2020\end{array}$ & 14 & $\begin{array}{l}\text { On } 1 \text { May, the Government of India (GOI) further extended the lockdown period } \\
\text { to two weeks beyond } 4 \text { May, with some relaxations. } \\
\text { Movement is permitted within green zones with buses limited to } 50 \text { percent } \\
\text { capacity. Orange zones would allow only private and hired vehicles but no } \\
\text { public transportation. The red zones would remain under complete lockdown. } \\
\text { The zone classification would be revised once a week. }\end{array}$ & 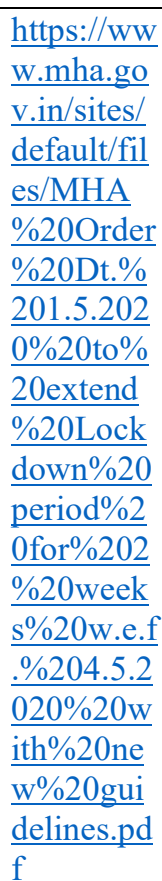 \\
\hline $\begin{array}{l}\text { Lockdo } \\
\text { wn } 4\end{array}$ & $\begin{array}{l}18 \\
\text { May, } \\
2020- \\
31 \\
\text { May, } \\
2020\end{array}$ & 14 & $\begin{array}{l}\text { On } 17 \text { May, GOI extended the lockdown for a period for two weeks from } 18 \\
\text { May, with } \\
\text { additional } \\
\text { Unlike the previous extensions, states were given a larger say in the demarcation } \\
\text { of Green, Orange and Red zones. Red zones were further divided into } \\
\text { containment and buffer zones. The local bodies were given the authority to } \\
\text { demarcate containment and buffer zones. }\end{array}$ & $\begin{array}{l}\text { https://ww } \\
\text { w.thehind } \\
\text { u.com/ne } \\
\text { ws/resour } \\
\text { ces/article } \\
\text { 31608347. } \\
\text { ece/binary } \\
\text { MHAOrd } \\
\text { erdatedM } \\
\text { ay17- } \\
\text { Guideline } \\
\text { sofLockd } \\
\text { ownexten } \\
\text { sion.pdf }\end{array}$ \\
\hline
\end{tabular}




\begin{tabular}{|c|c|c|c|c|}
\hline $\begin{array}{l}\text { Unlock } \\
1\end{array}$ & $\begin{array}{l}1 \text { June, } \\
2020- \\
30 \\
\text { June, } \\
2020\end{array}$ & 30 & $\begin{array}{l}\text { The MHA issued fresh guidelines for June, stating that the phases of reopening } \\
\text { would "have an economic focus". Lockdown restrictions were only to be } \\
\text { imposed in containment zones, while activities were permitted in other zones in } \\
\text { a phased } \\
\text { manner. } \\
\text { This first phase of reopening was termed "Unlock } 1.0 \text { " and permitted shopping } \\
\text { malls, religious places, hotels, and restaurants to reopen from } 8 \text { June. } \\
\text { Restrictions on interstate travel was relaxed. However, large gatherings were } \\
\text { still banned and night curfews were in effect from } 9 \text { p.m. to } 5 \text { a.m. in all areas } \\
\text { and state governments were allowed to impose additional restrictions on all } \\
\text { activities. }\end{array}$ & $\begin{array}{l}\underline{\text { https://ww }} \\
\text { w.mha.go } \\
\text { v.in/sites/ } \\
\text { default/fil } \\
\text { es/MHAO } \\
\underline{\text { rderDt } 30} \\
\underline{052020 . p d} \\
\underline{f}\end{array}$ \\
\hline $\begin{array}{l}\text { Unlock } \\
2\end{array}$ & $\begin{array}{l}1 \text { July, } \\
2020- \\
31 \text { July, } \\
2020\end{array}$ & 31 & $\begin{array}{l}\text { Phase II of Unlock began on } 1 \text { July. Lockdown measures were only imposed in } \\
\text { containment zones. In all other areas, most activities were permitted. However, } \\
\text { large gatherings were still prohibited and night curfews were in effect from } 10 \\
\text { p.m. }\end{array}$ & $\begin{array}{l}\frac{\text { https://ww }}{\text { w.mha.go }} \\
\text { v.in/sites/ } \\
\text { default/fil } \\
\text { es/MHAO } \\
\underline{\text { rder 2906 }} \\
\text { 2020.pdf }\end{array}$ \\
\hline & $\begin{array}{l}1 \text { Aug, } \\
2020- \\
31 \text { Aug, } \\
2020\end{array}$ & 31 & $\begin{array}{l}\text { Unlock } 3.0 \text { for August } 2020 \text { removed night curfews and permitted gymnasiums } \\
\text { and yoga centres to reopen after } 5 \text { August. Educational institutions remained } \\
\text { closed till } 31 \text { August. All inter-and intrastate travel and transportation are } \\
\text { permitted. } \\
\text { Independence Day celebrations are permitted with social distancing. } \\
\text { Maharashtra and Tamil Nadu imposed a lockdown for the whole month, while } \\
\text { West Bengal imposed lockdowns twice a week. On } 30 \text { August the Delhi Metro } \\
\text { started its operations with two metro lines }\end{array}$ & $\begin{array}{l}\frac{\text { https://ww }}{\text { w.mha.go }} \\
\text { v.in/sites/ } \\
\text { default/fil } \\
\text { es/DOLrD } \\
\text { t 290720 } \\
\text { 20.pdf }\end{array}$ \\
\hline $\begin{array}{l}\text { Unlock } \\
4\end{array}$ & $\begin{array}{l}1 \text { Sept, } \\
2020- \\
30 \text { Sept, } \\
2020\end{array}$ & 30 & $\begin{array}{l}\text { On } 29 \text { August } 2020 \text {, the GOI issued guidelines for activities permitted in Unlock } \\
\text { 4.0. Lockdown remained in force in the Containment Zones till 30th September } \\
\text { 2020. Outside the containment zone, however, additional activities were given } \\
\text { permission. } \\
\text { Metro Rail was allowed to be reopened in a graded manner from } 7 \text { September. } \\
\text { Marriage functions with gatherings of up to } 50 \text { people and funereal/last rites } \\
\text { ceremonies with up to } 20 \text { people were permitted. } \\
\text { Religious, entertainment, political, sports, academic functions and gatherings of } \\
\text { up to } 100 \text { people were allowed. }\end{array}$ & $\begin{array}{l}\text { https://ww } \\
\text { w.mha.go } \\
\text { v.in/sites/ } \\
\text { default/fil } \\
\text { es/MHAO } \\
\text { rder_Unlo } \\
\text { ck4_2908 } \\
\text { 2020.pdf }\end{array}$ \\
\hline
\end{tabular}




\begin{tabular}{|c|c|c|c|c|}
\hline $\begin{array}{l}\text { Unlock } \\
5\end{array}$ & $\begin{array}{l}1 \text { Oct, } \\
2020- \\
31 \text { Oct, } \\
2020\end{array}$ & 31 & 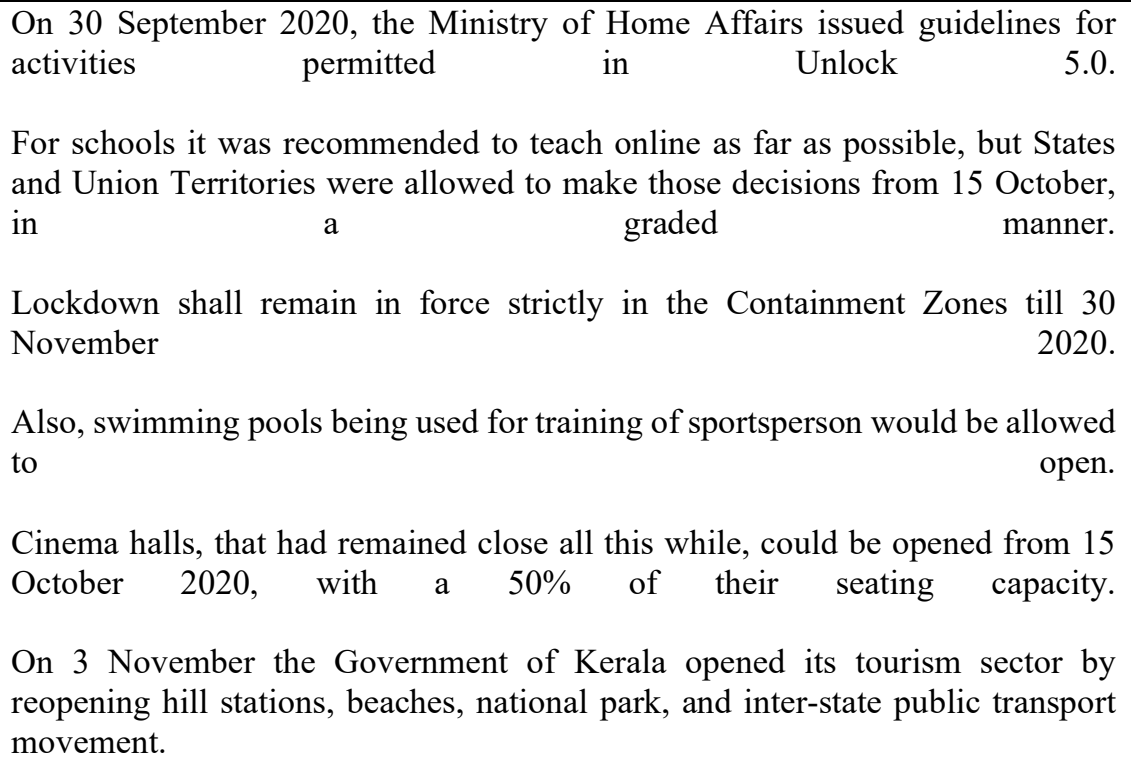 & $\begin{array}{l}\frac{\text { https://ww }}{\text { w.mha.go }} \\
\text { v.in/sites/ } \\
\underline{\text { default/fil }} \\
\text { es/MHAO } \\
\text { rderDt 30 } \\
\underline{\text { 092020.pd }} \\
\underline{f}\end{array}$ \\
\hline $\begin{array}{l}\text { Unlock } \\
6\end{array}$ & $\begin{array}{l}1 \text { Nov, } \\
2020- \\
30 \text { Nov, } \\
2020\end{array}$ & 30 & $\begin{array}{l}\text { On } 27 \text { October } 2020 \text {, the GOI issued guidelines for activities permitted in } \\
\text { Unlock } 6.0 \text {. No new changes were made to the existing Unlock } 5.0 \text { guidelines } \\
\text { and notified that Unlock } 5 \text { guidelines were to be in the month of November } \\
2020 \text {. } \\
\text { Also, a handful of states allowed opening up of more activities outside } \\
\text { containment zones and announced partial reopening of schools. Lockdown was } \\
\text { enforced time and again in spite of attempts to permanently move towards an } \\
\text { unlock } \\
\text { The GOI extended the ban on scheduled international passenger flights till } \\
\text { January } 31 \text {. }\end{array}$ & $\begin{array}{l}\underline{\text { https://ww }} \\
\text { w.india.co } \\
\text { m/news/in } \\
\text { dia/mha- } \\
\text { issues- } \\
\text { unlock-6- } \\
\text { guidelines } \\
\text {-check- } \\
\text { here- } \\
\text { whats- } \\
\text { allowed- } \\
\text { whats- } \\
\text { not-in- } \\
\text { november } \\
\text {-4187769/ }\end{array}$ \\
\hline
\end{tabular}

Table A2: Lockdown Phases and Restrictions

Notes: This table provides a summary of the extent of restrictions imposed on various activities by the Government of India between January and November 2020. 


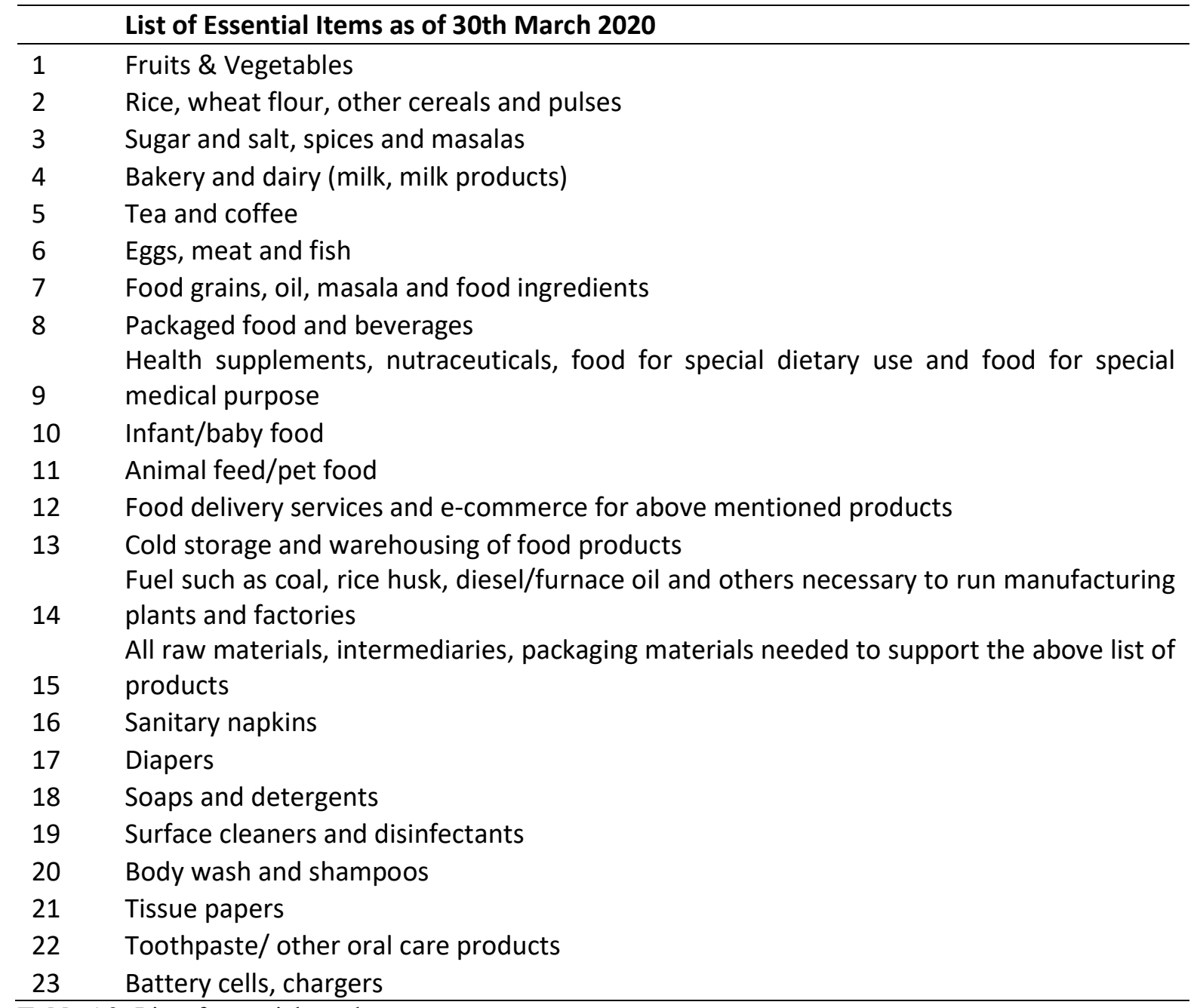

Table A3: List of essential goods

Source: https://www.bloombergquint.com/business/government-expands-list-of-essential-items-to-include-hygiene-products and https://seednet.gov.in/PDFFILES/Essential_Commodity_Act_1955(No_10_of_1955).pdf 


\begin{tabular}{lll}
\hline Dependent Variable: & Inter District Mobility & Within District Mobility \\
\hline & $(1)$ & $(2)$ \\
\hline Unemployment & $-1.030^{* * *}$ & $-0.518^{* * *}$ \\
& $(0.131)$ & $(0.100)$ \\
Constant & $503.437 * * *$ & $245.222^{* * *}$ \\
& $(2.155)$ & $(1.647)$ \\
& & \\
State FE & Yes & Yes \\
Day of Year FE & Yes & Yes \\
Observations & 4,392 & 4,392 \\
Adjusted R-squared & 0.994 & 0.984 \\
\hline
\end{tabular}

Table A4: Regression with inter-district Facebook-migration as the dependent variable in column (1) and within-district Facebook-migration in column (2). Sample covers the entire unlock period starting with the month of May 2020 till the end of the data. Standard errors in parentheses: ${ }^{* * *} \mathrm{p}<0.01,{ }^{* *} \mathrm{p}<0.05, * \mathrm{p}<0.1$ 


\begin{tabular}{|c|c|c|}
\hline \multicolumn{3}{|c|}{ Dependent Variable: Total Confirmed Covid19 per million population } \\
\hline & $(1)$ & $(2)$ \\
\hline & Column-8 (Table 3) & + NonLinear-Time \\
\hline \multirow[t]{2}{*}{ Nightlight inequality } & $0.476 * * *$ & $0.493 * * *$ \\
\hline & $(0.139)$ & $(0.137)$ \\
\hline \multirow{2}{*}{ Days since 1 Jan, 2020} & $-0.008 * * *$ & $0.126 * * *$ \\
\hline & $(0.001)$ & $(0.002)$ \\
\hline \multirow[t]{2}{*}{ Days-squared } & & $-0.000 * * *$ \\
\hline & & $(0.000)$ \\
\hline \multirow[t]{2}{*}{ Nightlight } & $0.072 * * *$ & $0.073^{* * *}$ \\
\hline & $(0.002)$ & $(0.002)$ \\
\hline \multirow[t]{2}{*}{ Daily Covid tests } & $0.000 * * *$ & $0.000 * * *$ \\
\hline & $(0.000)$ & $(0.000)$ \\
\hline \multirow[t]{2}{*}{ Population density } & $-0.000 * * *$ & $-0.000 * * *$ \\
\hline & $(0.000)$ & $(0.000)$ \\
\hline \multirow[t]{2}{*}{ Temperature } & $-0.094 * * *$ & $-0.105^{* * *}$ \\
\hline & $(0.006)$ & $(0.006)$ \\
\hline \multirow[t]{2}{*}{ Rainfall } & $0.020 * * *$ & $0.003 * *$ \\
\hline & $(0.001)$ & $(0.001)$ \\
\hline \multirow[t]{2}{*}{ BCG vaccination } & $0.007 * *$ & $0.006 * *$ \\
\hline & $(0.003)$ & $(0.003)$ \\
\hline \multirow[t]{2}{*}{ Total vaccine } & $0.009 * * *$ & $0.011^{* * *}$ \\
\hline & $(0.002)$ & $(0.002)$ \\
\hline \multirow[t]{2}{*}{ Colonial malaria } & $-0.142 * * *$ & $-0.133 * * *$ \\
\hline & $(0.017)$ & $(0.017)$ \\
\hline \multirow[t]{2}{*}{ Latitude } & $-0.071 * * *$ & $-0.072 * * *$ \\
\hline & $(0.015)$ & $(0.014)$ \\
\hline \multirow[t]{2}{*}{ Longitude } & $-0.053 * * *$ & $-0.061 * * *$ \\
\hline & $(0.012)$ & $(0.012)$ \\
\hline \multirow[t]{2}{*}{ Constant } & $13.799 * * *$ & -0.673 \\
\hline & $(1.024)$ & $(1.029)$ \\
\hline State FE & Yes & Yes \\
\hline State Trend & Yes & Yes \\
\hline Observations & 139,309 & 139,309 \\
\hline Adjusted R-squared & 0.157 & 0.184 \\
\hline
\end{tabular}

Table A5: Baseline with neighbourhood nightlight-inequality and state fixed effect. Column (2) additionally allows for non-linear time trend. Nightlight Inequality, Average district level nightlight, population density, latitude, longitude, BCG vaccination (in 2017), total vaccination (in 2017) and colonial malaria vary at the district level. Covid19 daily tested varies by state-day. Standard errors in parentheses: $* * * \mathrm{p}<0.01, * * \mathrm{p}<0.05, * \mathrm{p}<0.1$ 


\begin{tabular}{|c|c|c|c|c|c|c|c|c|}
\hline \multicolumn{9}{|c|}{ Dependent Variable: Total Confirmed Covid19 per million population } \\
\hline & $(1)$ & $(2)$ & (3) & $(4)$ & $(5)$ & $(6)$ & $(7)$ & $(8)$ \\
\hline $\begin{array}{l}\text { Nightlight } \\
\text { Inequality }\end{array}$ & $\begin{array}{c}1.836^{* * *} \\
(0.141)\end{array}$ & $\begin{array}{c}1.097^{* * *} \\
(0.141)\end{array}$ & $\begin{array}{c}1.066^{* * *} \\
(0.141)\end{array}$ & $\begin{array}{c}1.019^{* * *} \\
(0.141)\end{array}$ & $\begin{array}{c}0.847^{* * *} \\
(0.141)\end{array}$ & $\begin{array}{c}1.021^{* * *} \\
(0.145)\end{array}$ & $\begin{array}{c}0.989 * * * \\
(0.145)\end{array}$ & $\begin{array}{c}0.892^{* * *} \\
(0.142)\end{array}$ \\
\hline Border District & $\begin{array}{c}-0.691 * * * \\
(0.038)\end{array}$ & $\begin{array}{c}-0.509 * * * \\
(0.038)\end{array}$ & $\begin{array}{c}-0.528^{* * *} \\
(0.038)\end{array}$ & $\begin{array}{c}-0.523^{* * *} \\
(0.038)\end{array}$ & $\begin{array}{c}-0.488^{* * *} \\
(0.038)\end{array}$ & $\begin{array}{c}-0.500 * * * \\
(0.038)\end{array}$ & $\begin{array}{c}-0.500 * * * \\
(0.038)\end{array}$ & $\begin{array}{c}-0.515^{* * *} \\
(0.037)\end{array}$ \\
\hline \multicolumn{9}{|l|}{ Days since Jan 1 . } \\
\hline 2020 & & $\begin{array}{c}-0.010 * * * \\
(0.000)\end{array}$ & $\begin{array}{c}-0.010 * * * \\
(0.000)\end{array}$ & $\begin{array}{c}-0.010 * * * \\
(0.000)\end{array}$ & $\begin{array}{c}-0.011^{* * *} \\
(0.000)\end{array}$ & $\begin{array}{c}-0.011 * * * \\
(0.000)\end{array}$ & $\begin{array}{c}-0.011^{* * *} \\
(0.000)\end{array}$ & $\begin{array}{c}-0.008^{* * *} \\
(0.001)\end{array}$ \\
\hline Nightlight & & $\begin{array}{c}0.052^{* * *} \\
(0.001)\end{array}$ & $\begin{array}{c}0.070 * * * \\
(0.002)\end{array}$ & $\begin{array}{c}0.071 * * * \\
(0.002)\end{array}$ & $\begin{array}{c}0.071 * * * \\
(0.002)\end{array}$ & $\begin{array}{c}0.070 * * * \\
(0.002)\end{array}$ & $\begin{array}{c}0.070 * * * \\
(0.002)\end{array}$ & $\begin{array}{c}0.071 * * * \\
(0.002)\end{array}$ \\
\hline Daily tested & & $\begin{array}{c}0.032^{* * *} \\
(0.001)\end{array}$ & $\begin{array}{c}0.032^{* * *} \\
(0.001)\end{array}$ & $\begin{array}{c}0.031^{* * *} \\
(0.001)\end{array}$ & $\begin{array}{c}0.031 * * * \\
(0.001)\end{array}$ & $\begin{array}{c}0.032 * * * \\
(0.001)\end{array}$ & $\begin{array}{c}0.032^{* * *} \\
(0.001)\end{array}$ & $\begin{array}{c}0.050 * * * \\
(0.001)\end{array}$ \\
\hline Population density & & & $\begin{array}{c}-0.095 * * * \\
(0.006)\end{array}$ & $\begin{array}{c}-0.099 * * * \\
(0.007)\end{array}$ & $\begin{array}{c}-0.099 * * * \\
(0.006)\end{array}$ & $\begin{array}{c}-0.097 * * * \\
(0.006)\end{array}$ & $\begin{array}{c}-0.099 * * * \\
(0.006)\end{array}$ & $\begin{array}{c}-0.101^{* * *} \\
(0.006)\end{array}$ \\
\hline Temperature & & & & $\begin{array}{l}-0.001 \\
(0.005)\end{array}$ & $\begin{array}{c}-0.015 * * * \\
(0.005)\end{array}$ & $\begin{array}{c}-0.012^{* *} \\
(0.005)\end{array}$ & $\begin{array}{c}-0.012^{* *} \\
(0.005)\end{array}$ & $\begin{array}{c}-0.096 * * * \\
(0.006)\end{array}$ \\
\hline Rainfall & & & & $\begin{array}{c}0.026 * * * \\
(0.001)\end{array}$ & $\begin{array}{c}0.026 * * * \\
(0.001)\end{array}$ & $\begin{array}{c}0.024 * * * \\
(0.001)\end{array}$ & $\begin{array}{c}0.024 * * * \\
(0.001)\end{array}$ & $\begin{array}{c}0.020^{* * *} \\
(0.001)\end{array}$ \\
\hline BCG vaccination & & & & & $\begin{array}{c}0.002 \\
(0.003)\end{array}$ & $\begin{array}{c}0.004 \\
(0.003)\end{array}$ & $\begin{array}{c}0.005 \\
(0.003)\end{array}$ & $\begin{array}{c}0.005 \\
(0.003)\end{array}$ \\
\hline Total vaccination & & & & & $\begin{array}{c}0.012^{* * *} \\
(0.002)\end{array}$ & $\begin{array}{c}0.010 * * * \\
(0.002)\end{array}$ & $\begin{array}{c}0.008 * * * \\
(0.002)\end{array}$ & $\begin{array}{c}0.008^{* * *} \\
(0.002)\end{array}$ \\
\hline Colonial malaria & & & & & & $\begin{array}{c}-0.149 * * * \\
(0.017)\end{array}$ & $\begin{array}{c}-0.134^{* * *} \\
(0.018)\end{array}$ & $\begin{array}{c}-0.138^{* * *} \\
(0.017)\end{array}$ \\
\hline Latitude & & & & & & & $\begin{array}{c}-0.056 * * * \\
(0.015)\end{array}$ & $\begin{array}{c}-0.069 * * * \\
(0.015)\end{array}$ \\
\hline Longitude & & & & & & & $\begin{array}{c}-0.059 * * * \\
(0.012)\end{array}$ & $\begin{array}{c}-0.055^{* * *} \\
(0.012)\end{array}$ \\
\hline Constant & $\begin{array}{c}2.207^{* * *} \\
(0.121)\end{array}$ & $\begin{array}{c}3.768^{* * *} \\
(0.133)\end{array}$ & $\begin{array}{c}3.797^{* * *} \\
(0.132)\end{array}$ & $\begin{array}{c}3.631^{* * *} \\
(0.273)\end{array}$ & $\begin{array}{c}3.623^{* * *} \\
(0.350)\end{array}$ & $\begin{array}{c}3.928 * * * \\
(0.356)\end{array}$ & $\begin{array}{c}9.877^{* * *} \\
(1.037)\end{array}$ & $\begin{array}{c}14.232 * * * \\
(1.024)\end{array}$ \\
\hline State FE & Yes & Yes & Yes & Yes & Yes & Yes & Yes & Yes \\
\hline State & No & No & No & No & No & No & No & Yes \\
\hline Obser & 148,737 & 147,875 & 147,875 & 147,473 & 145,640 & 139,309 & 139,309 & 139,309 \\
\hline Adjusted R-squared & 0.088 & 0.115 & 0.116 & 0.117 & 0.117 & 0.120 & 0.120 & 0.158 \\
\hline
\end{tabular}

Table A6: This Table corresponds to Table 3. All columns additionally control for an indicator reflecting whether a district is located at a state border. Nightlight Inequality, Average district level nightlight, population density, normalized by 1000, latitude, longitude, BCG vaccination (in 2017), total vaccination (in 2017) and colonial malaria vary at the district level. Covid19 daily tested, normalized by 1000 , varies by state-day. Standard errors in parentheses: $* * * p<0.01,{ }^{* *} p<0.05,{ }^{*} p<0.1$ 


\begin{tabular}{|c|c|c|c|c|c|c|}
\hline \multicolumn{7}{|c|}{ Dependent Variable: Total Confirmed Covid19 per million population } \\
\hline & (1) & (2) & (3) & (4) & $(5)$ & (6) \\
\hline & \multicolumn{2}{|c|}{ Lockdown } & \multicolumn{4}{|c|}{ Unlock } \\
\hline & $\begin{array}{l}\text { 4-17 May } \\
2020\end{array}$ & $\begin{array}{c}\text { 18-31 May } \\
2020\end{array}$ & $\begin{array}{c}\text { September } \\
2020\end{array}$ & $\begin{array}{c}\text { October } \\
2020\end{array}$ & $\begin{array}{c}\text { November } \\
2020\end{array}$ & $\begin{array}{c}\text { December } \\
2020\end{array}$ \\
\hline Industrial & 3.997 & -9.727 & $93.785 * * *$ & $14.053 * * *$ & 5.833 & $19.651 * * *$ \\
\hline & $(5.205)$ & $(6.001)$ & $(5.369)$ & $(4.105)$ & $(6.262)$ & $(2.863)$ \\
\hline Days since Jan 1.2020 & $\begin{array}{c}0.023 \\
(0.453)\end{array}$ & $\begin{array}{c}0.168 \\
(0.504)\end{array}$ & $\begin{array}{l}-0.029 \\
(0.207)\end{array}$ & $\begin{array}{l}-0.000 \\
(0.153)\end{array}$ & $\begin{array}{c}-0.488 * * \\
(0.237)\end{array}$ & $\begin{array}{c}-0.863^{* * *} \\
(0.109)\end{array}$ \\
\hline Nightlight & $\begin{array}{c}0.020 \\
(0.062)\end{array}$ & $\begin{array}{c}-0.223 * * * \\
(0.082)\end{array}$ & $\begin{array}{c}3.169 * * * \\
(0.074)\end{array}$ & $\begin{array}{c}2.684 * * * \\
(0.057)\end{array}$ & $\begin{array}{c}2.604 * * * \\
(0.085)\end{array}$ & $\begin{array}{c}1.224 * * * \\
(0.039)\end{array}$ \\
\hline Daily tested & $\begin{array}{c}-0.014 \\
(0.192)\end{array}$ & $\begin{array}{c}0.019 \\
(0.231)\end{array}$ & $\begin{array}{c}0.359 * * * \\
(0.034)\end{array}$ & $\begin{array}{c}0.355^{* * *} \\
(0.032)\end{array}$ & $\begin{array}{c}0.111^{* * *} \\
(0.032)\end{array}$ & $\begin{array}{c}0.199 * * * \\
(0.025)\end{array}$ \\
\hline Population density & $\begin{array}{c}0.377 \\
(0.705)\end{array}$ & $\begin{array}{c}2.676 * * * \\
(0.926)\end{array}$ & $\begin{array}{c}-26.244^{* * *} \\
(0.843)\end{array}$ & $\begin{array}{c}-19.297 * * * \\
(0.643)\end{array}$ & $\begin{array}{c}-18.772 * * * \\
(0.968)\end{array}$ & $\begin{array}{c}-7.867 * * * \\
(0.440)\end{array}$ \\
\hline Temperature & $\begin{array}{c}-0.765^{* * *} \\
(0.165)\end{array}$ & $\begin{array}{l}-0.050 \\
(0.184)\end{array}$ & $\begin{array}{c}-1.269 * * * \\
(0.229)\end{array}$ & $\begin{array}{c}-1.342 * * * \\
(0.172)\end{array}$ & $\begin{array}{c}-2.377 * * * \\
(0.318)\end{array}$ & $\begin{array}{c}-0.453 * * * \\
(0.101)\end{array}$ \\
\hline Rainfall & $\begin{array}{l}-0.193 \\
(0.123)\end{array}$ & $\begin{array}{c}0.004 \\
(0.101)\end{array}$ & $\begin{array}{l}-0.019 \\
(0.024)\end{array}$ & $\begin{array}{l}-0.002 \\
(0.033)\end{array}$ & $\begin{array}{l}-0.058 \\
(0.074)\end{array}$ & $\begin{array}{l}-0.036 \\
(0.051)\end{array}$ \\
\hline BCG vaccination & $\begin{array}{c}0.216^{* * * *} \\
(0.061)\end{array}$ & $\begin{array}{c}0.082 \\
(0.077)\end{array}$ & $\begin{array}{l}-0.095 \\
(0.070)\end{array}$ & $\begin{array}{l}-0.075 \\
(0.053)\end{array}$ & $\begin{array}{c}0.104 \\
(0.081)\end{array}$ & $\begin{array}{l}-0.006 \\
(0.037)\end{array}$ \\
\hline Total vaccination & $\begin{array}{c}-0.121 * * * \\
(0.038)\end{array}$ & $\begin{array}{l}-0.038 \\
(0.046)\end{array}$ & $\begin{array}{c}0.482 * * * \\
(0.042)\end{array}$ & $\begin{array}{c}0.351 * * * \\
(0.032)\end{array}$ & $\begin{array}{c}0.138 * * * \\
(0.048)\end{array}$ & $\begin{array}{c}0.236 * * * \\
(0.022)\end{array}$ \\
\hline Colonial malaria & $\begin{array}{c}-2.334 * * * \\
(0.349)\end{array}$ & $\begin{array}{c}-1.878 * * * \\
(0.434)\end{array}$ & $\begin{array}{c}2.636^{* * *} \\
(0.386)\end{array}$ & $\begin{array}{c}-2.140 * * * \\
(0.294)\end{array}$ & $\begin{array}{c}-7.206 * * * \\
(0.443)\end{array}$ & $\begin{array}{c}-1.533 * * * \\
(0.201)\end{array}$ \\
\hline Latitude & $\begin{array}{c}0.850 * * * \\
(0.292)\end{array}$ & $\begin{array}{l}-0.353 \\
(0.360)\end{array}$ & $\begin{array}{c}-0.785^{* *} \\
(0.327)\end{array}$ & $\begin{array}{c}-1.187 * * * \\
(0.250)\end{array}$ & $\begin{array}{l}-0.435 \\
(0.399)\end{array}$ & $\begin{array}{c}0.304 \\
(0.187)\end{array}$ \\
\hline Longitude & $\begin{array}{c}-0.561 * * \\
(0.243)\end{array}$ & $\begin{array}{c}-1.181 * * * \\
(0.299)\end{array}$ & $\begin{array}{l}-0.202 \\
(0.269)\end{array}$ & $\begin{array}{c}0.979 * * * \\
(0.205)\end{array}$ & $\begin{array}{c}2.404 * * * \\
(0.313)\end{array}$ & $\begin{array}{c}0.662 * * * \\
(0.143)\end{array}$ \\
\hline Constant & $\begin{array}{c}35.780 \\
(24.643)\end{array}$ & $\begin{array}{c}107.397 * * * \\
(29.556)\end{array}$ & $\begin{array}{c}80.060 * * * \\
(28.360)\end{array}$ & $\begin{array}{c}255.917^{* * *} \\
(23.103)\end{array}$ & $\begin{array}{c}39.426 \\
(38.179)\end{array}$ & $\begin{array}{c}103.813 * * * \\
(19.819)\end{array}$ \\
\hline State FE & Yes & Yes & Yes & Yes & Yes & Yes \\
\hline State Trend & Yes & Yes & Yes & Yes & Yes & Yes \\
\hline Observations & 6,105 & 6,920 & 15,461 & 15,883 & 15,121 & 14,870 \\
\hline Adjusted R-squared & 0.146 & 0.104 & 0.524 & 0.583 & 0.342 & 0.576 \\
\hline
\end{tabular}

Table A7: Regression with industrial heterogeneity index for Unlock phases 1-8. Average nightlight, population density, latitude, longitude, BCG vaccination (in 2017), total vaccination (in 2017) and colonial malaria vary at the district level. Covid19 daily tested varies by state-day. Standard errors in parentheses: $* * * p<0.01, * * p<0.05, * p<0.1$ 